RPP-31314

Revision 0

\title{
A Comprehensive
} Technical Review of the Demonstration Bulk Vitrification System Technical Assessment Conducted by an Independent and External Team of Experts, September 28, 2006

\section{Volume 1}

Charlered by $\mathrm{CH} 2 \mathrm{M}$ HILL Hanford, Inc., Richland, Washington 99352

Prepared for the U.S. Department of Energy

Assistant Secretary for Environmental Management

Contractor lor the U.S. Department of Energy

Office of River Prolection under Contract DE-AC27-99RL14047

\section{eIH2INHILL Hanford Group, Inc.}

P.O. Box 1500

Richland, Washington

Approved for Public Release;

Further Dissemination Unlimited 
RPP-31314

Revision 0

\title{
A Comprehensive Technical Review of the Demonstration Bulk Vitrification System
}

Technical Assessment Conducted by an Independent and External Team of Experts, September 28, 2006 Volume 1

Chartered by $\mathrm{CH} 2 \mathrm{M}$ HILL Hanford, Inc., Richland, Washington 99352

\author{
J. O. Honeyman \\ P.S. Schaus \\ CH2M HILL Hanford Group, Inc.
}

Date Published

September 2006

Prepared for the U.S. Department of Energy

Assistant Secretary for Environmental Management

Contractor for the U.S. Department of Energy

Office of River Protection under Contract DE-AC27-99RL14047

\section{CH2NIHILL \\ Hanford Group, Inc.}

P.O. Box 1500

Richland, Washington

A. Di. Aasulal og/29/2006 
RPP-31314

Revision 0

TRADEMARK DISCLAIMER

Reference herein to any specific commercial product, process,

or service by trade name, trademark, manufacturer, or

otherwise, does not necessarily conslitute or imply its

endorsement, recommendation, or favoring by the United

States Government or any agency thereof or its contractors or subcontractors

This report has been reproduced from the best available copy.

Pimlod in the Unied Stater of Ametica 


\section{Executive Summary}

In May 2006, CH2M HILL Hanford Group, Inc. chartered an Expert Review Panel (ERP) to review the current status of the Demonstration Bulk Vitrification System (DBVS). It is the consensus of the ERP that bulk vitrification is a technology that requires further development and evaluation to determine its potential for meeting the Hanford waste stabilization mission. No fatal flaws (issues that would jeopardize the overall DBVS mission that cannot be mitigated) were found, given the current state of the project. However, a number of technical issues were found that could significantly affect the project's ability to meet its overall mission as stated in the project Justification of Mission Need document, if not satisfactorily resolved.

The ERP recognizes that the project has changed from an accelerated schedule demonstration project to a formally chartered project that must be in full compliance with DOE 413.3 requirements. The perspective of the ERP presented herein, is measured against the formally chartered project as stated in the approved Justification of Mission Need document.

A Justification of Mission Need document was approved in July 2006 which delined the objectives for the DBVS Project. In this document, DOE concluded that bulk vitrification is a viable technology that requires additional development to determine its potential applicability to treatment of a portion of the Hanford low activity waste. The DBVS mission need statement now includes the following primary objectives:

- Process approximately 190,000 gallons of Tank S-109 waste into fifty 100 metric ton boxes of vitrified product.

- Store and dispose of these boxes at Hanford's Integrated Disposal Facility (IDF)

- Evaluate the waste form characteristics.

- Gather pilot plant operability data, and

- Develop the overall life cycle system performance of bulk vitrification and produce a comparison of the bulk vitrification process to building a second LAW Immobilization facility or other supplemental treatment alternatives as provided in $\mathrm{M}-62-08$.

While the DBVS is clearly poised to meet the first three objectives, the project must expeditiously develop plans to achieve the last two and develop clear success criteria to determine whether they have been met.

A surmmary of the key issues that need technical and management actions follows.

- Additional cold testing is needed to underpin process design and operations (e.g., flow of dried waste feed, prevention of secondary phases, and balancing of the off-gas systems) before radioactive feed is introduced. 
- The mixer-dryer and off-gas systems need special attention in the next project phase, as most of the development work to date has been focused on the In Container Vitrification ${ }^{\mathrm{TM}}$ process.

- System complexity should be reduced to enhance system operability and availability.

- Process sampling and monitoring plans should be improved to assure that essential operational and needed $R \& D$ data from DBVS test runs are captured.

- A better understanding of the DBVS process flowsheet from a chemical point of view is critical to success, both in building a high reliability production plant and in troubleshooting and recovering from any problems that occur during operation.

- The feed compositions to be tested in the DBVS Project should reflect the spectrum of wastes expected to be processed by bulk vitrification so that a comparison to other supplemental treatment alternatives can be made.

- Potential nuclear safety issues, including confinement strategy, implementation of Integrated Safety Management, and response to off-normal events, need to be resolved before startup of radioactive waste processing.

- The project needs to ensure that its designs and specifications meet the required codes and standards.

- The process to identify and manage risks has been developed, needs to be improved, and must be effectively utilized in future stages of the project.

The ERP identified:

- 19 technical issues which could result in a failure of the DBVS demonstration system to meet established DBVS system performance requirements unless addressed prior to startup of hot operations

- 26 areas of concern which may result in a change to design or require additional testing to determine if the design is adequate (now or later)

- 13 suggested improvements the project should consider to enhance safety, cost, schedule, or efficiency during the test operations, and the potential transition to a production system downstream.

The ERP charter focused this review on the technical basis for the existing DBVS design. This team did not review overall project cost and schedule estimates, nor did it specifically evaluate the efficacy of bulk vitrification technology implementation versus other alternative treatment pathways DOE may choose in the future.

DOE and CH2M HILL are to be commended for commissioning this review at an early enough stage in the project so that the issues identified can be acted upon in a timely manner. The ERP recommends that the project conduct periodic reviews in the future at key decision points within the DBVS Project to assure that these issues and others that may arise are identified and resolved. 


\section{Acronyms/Abbreviations}

\begin{tabular}{|c|c|}
\hline ALARA & as low as reasonably achievable \\
\hline AMEC & AMEC Earth and Environment Inc. \\
\hline AWTE & ancillary waste transfer enclosure \\
\hline CH2M HILL & CH2M HILL Hanford Group, Inc. \\
\hline CRB & castable refractory block \\
\hline D\&D & decontamination and decommissioning \\
\hline DBVS & Demonstration Bulk Vitrification System \\
\hline DOD & Department of Defense \\
\hline DOE & U.S. Department of Energy \\
\hline $\mathrm{DQO}$ & Data Quality Objective \\
\hline DRE & Destruction Removal Efficiency \\
\hline DWTS & Dried Waste Transfer System \\
\hline EDTA & ethylene diamine tetraacetic acid \\
\hline ERP & Expert Review Panel \\
\hline ETF & Effluent Treatment Facility \\
\hline GFE & government furnished equipment \\
\hline $\mathrm{HC}$ & Hazard Categorization \\
\hline HEGA & high-efficiency gas adsorper \\
\hline HEPA & high-efficiency particulate air \\
\hline $\mathrm{HLW}$ & High-Level Waste \\
\hline $\mathrm{ICV} \mathrm{V}^{\mathrm{TM}}$ & In Container Vitrification ${ }^{\mathrm{TM}}$ \\
\hline IDF & Integrated Disposal Facility \\
\hline ISM & Integrated Safety Management \\
\hline ITEMP & Integrated Testing and Evaluation Management Plan \\
\hline $\mathrm{JMN}$ & Justification of Mission Need \\
\hline LAW & Low-Activity Waste \\
\hline MAR & Material at Risk \\
\hline OGTS & Ofr-Gas Treatment System \\
\hline ORP & Office of River Protection \\
\hline PDSA & Preliminary Documented Safety Analysis \\
\hline PEP & Project Execution Plan \\
\hline PSM & Process Safety Management \\
\hline RAM & Reliability, Availability, and Maintenance \\
\hline $\mathrm{RCM}$ & reliability-centered maintenance \\
\hline RD\&D & Research, Development and Demonstration \\
\hline SCR & selective catalytic reduction \\
\hline SMF & Sintered Metal Filter \\
\hline SWTS & Solid Waste Treatment System \\
\hline TRUM & Transuranic and Mixed Waste \\
\hline TSR & Technical Safety Requirement \\
\hline WTP & Waste Treatment Plant \\
\hline
\end{tabular}




\section{Table of Contents}

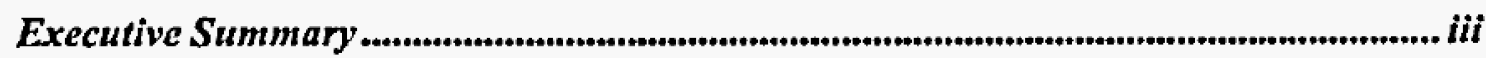

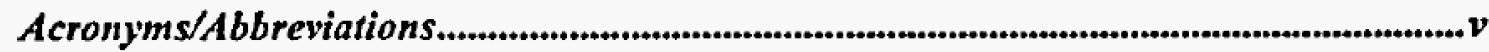

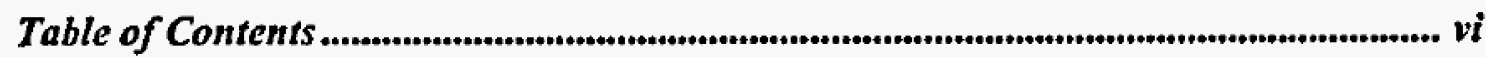

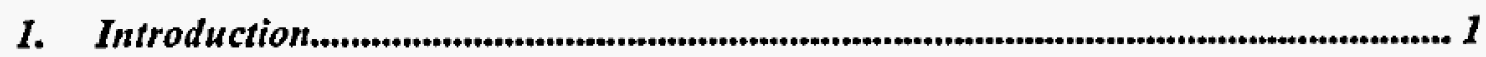

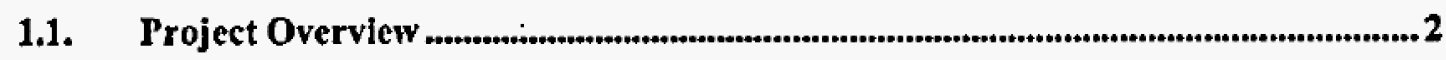

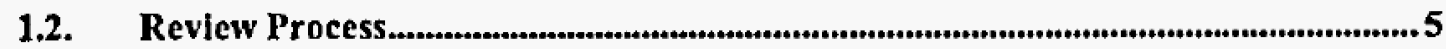

13. Review of the Demonstration Bulk Vitrification System Technical Basis................ 6

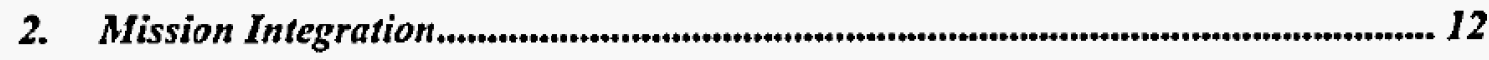

2.1. Justification of Mission Need............................................................................... 12

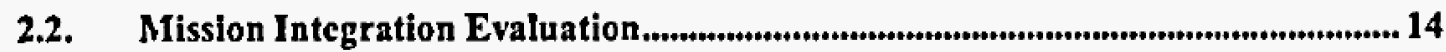

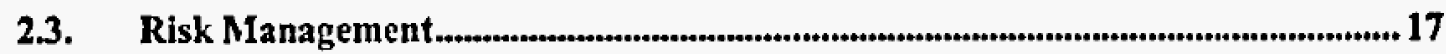

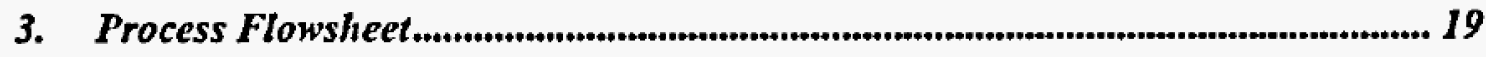

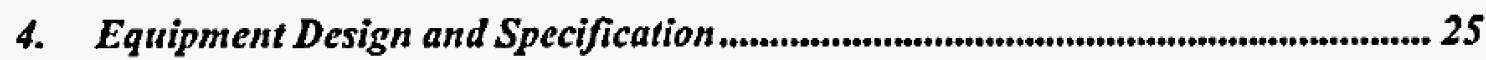

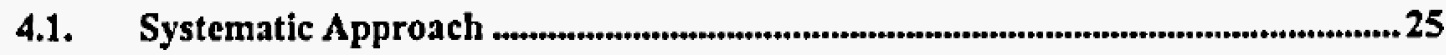

4.2. Liquid Waste Feed Systems ................................................................................. 25

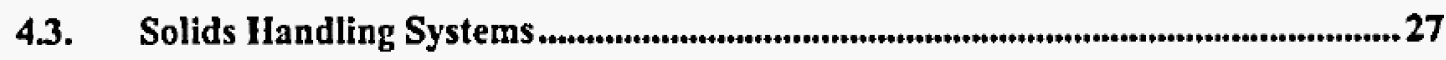

4.4. Mixer/Dryer .......................................................................................................... 29

4.5. Melter System and Vitrification Process................................................................. 32

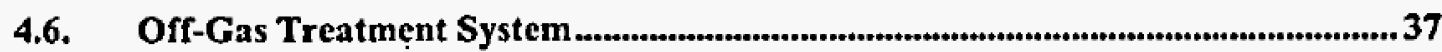

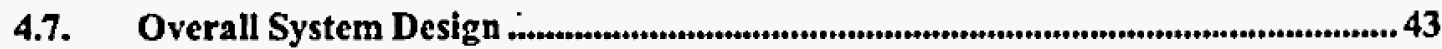

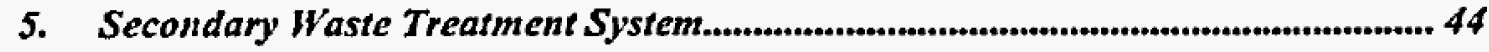

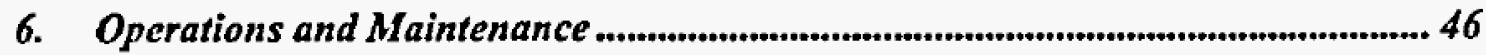

6.1. Operations and Maintenance Background .............................................................4 46

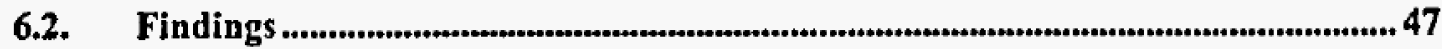

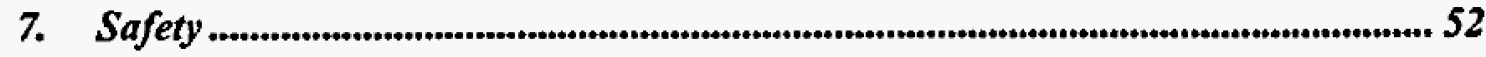

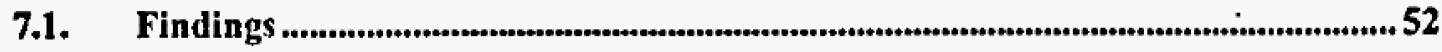

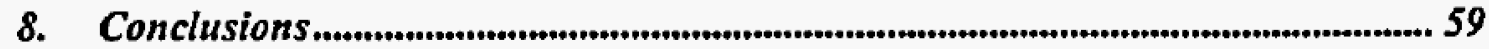




\section{Introduction}

The Department of Energy's (DOE) Office of River Protection (ORP) is charged with the safe management, retrieval, treatment and disposal of over 53 million gallons of radioactive hazardous chemical wastes currently stored in 177 aging underground singleshell and double-shell tanks at the Hanford site near Richland, Washington. Currently, a large Waste Treatment Plant (WTP) is under construction to separate the retrieved tank waste into high-level waste (HLW) and low-activity waste (LAW) fractions and to vitrify those separated wastes for either onsite disposal as LAW, or for offsite disposal at the proposed Yucca Mountain national repository as HLW. Completion of waste retrieval, treatment and disposal, as well as tank farm closure, will eliminate much of the risk posed by the tank waste to the Hanford groundwater, the Columbia River, and the public.

With its current design capacity, WTP, once fully operational, is expected to complete vitrification of the HLW in approximately 20-25 years. However, with WTP's existing design capacity for the LAW fraction, it is anticipated that a processing period significantly exceeding 25 years will be required. Additional LAW vitrification capability could be constructed to produce a balanced system that would result in a processing duration similar to that for the HLW fraction; acceleration of risk reduction to the environment and public; and potentially significant savings to the taxpayer.

DOE is considering approaches to provide this additional capability, either by expanding the existing WTP low-activity waste capability or by developing and deploying supplemental treatment technologies which might prove to be more cost effective. One of the candidates for supplemental treatment is an adaptation of In Container Vitrification ${ }^{T M}\left(\mathrm{ICV}^{\mathrm{TM}}\right.$ ) technology available from AMEC Earth and Environmental, Inc. (AMEC).

DOE has contracted with CH2M HILL Hanford Group, Inc. (CH2M HILLL) to design and construct a full scale demonstration system to test this technology with radioactive tank waste. This Demonstration Bulk Vitrification System (DBVS) project is currently in design and development with plans to initiate construction within the next two years.

In order to assure itself and DOE that the DBVS design is robust and likely to be successful, CH2M HILL proposed to conduct an external review of the current state of the design and development of the DBVS system prior to the formal decision (CD-3) to start construction of the project. A group of 16 independent experts and consultants, representing a broad spectrum of technology experts, academia, and nuclear waste processing industry experts, was identified and chartered as the Expert Review Panel (ERP). ORP and DOE's Office of Environmental Management participated in the selection of the Expert Review Panel members.

The objective of the ERP was to determine whether the DBVS system, as designed, could be expected to:

- meet the requirements defined in the system specification 
- produce a waste product that meets Hanford's Integrated Disposal Facility (IDF) disposal requircments

- receive operational approval by DOE authorities and other regulators.

\subsection{Demonstration Bulk Vitrification System Project Overview}

The DBVS Project has conducted an extensive set of process tests ranging from crucible melts of both simulants and radioactive tank wastes, cold (non-radioactive) and hot (radioactive) engineering scale melts, and a series of full scale cold melts. A series of supporting science and technology activities (e.g., glass formulation, investigation of unexpected second phase formation, and the pathway of technetium) have been conducted as well.

To date, the vast majority of the supporting technology development and demonstration efforts have focused on glass formulation, performance of the melter system at a successively larger scale, and testing and troubleshooting the prototypic melt system. The design of other major components of the demonstration system have largely relied on limited vendor testing or vendor performance claims, with few efforts directed towards scaled or full scalc testing of feed, material handling, or off-gas systems. In the current project plan, all integrated system testing will be conducted as part of the cold commissioning of the DBVS system.

The project was completing the detailed DBVS design in parallel with this ERP review. The detailed design was completed by AMEC on July 28,2006 . Similarly, a revised Documented Safcty Analysis was being prepared during this review. As a result, this review is a snapshot of a work-in-progress.

\section{Demonstration Bulk Vitrification System Description}

The DBVS is a full-scale test facility that will receive waste from single-shell tank 241-S109 , mix the waste with soil, dry the soil/waste mixture, and blend in glass former additives to produce a dried waste/additive mixture. The DBVS will then use the ICVTM process to convert the dried mixture into boxes of vitrified waste. The ICV ${ }^{\text {rM }}$ boxes will be cooled and interim stored until they are transferred to the Integrated Disposal Facility for disposal onsite. The DBVS will treat the process off-gas to a level that is protective of human health and the environment and meets applicable requirements. Secondary liquid wastes will be filtered and sent to the Effluent Treatment Facility (ETF) for treatment and disposal. Figure 1 shows the relationship between the main process systems in the DBVS. These process systems inlcude:

- Clean Soil System

- Waste Receipt System

- Waste Mixer/Dryer and Condensate Recovery Systems

- Dried Waste Handling System

- In-Container Vitrification ${ }^{\mathrm{TM}}$ System 
- Off-Gas Treatment System (OGTS)

- Secondary Waste Stórage System.

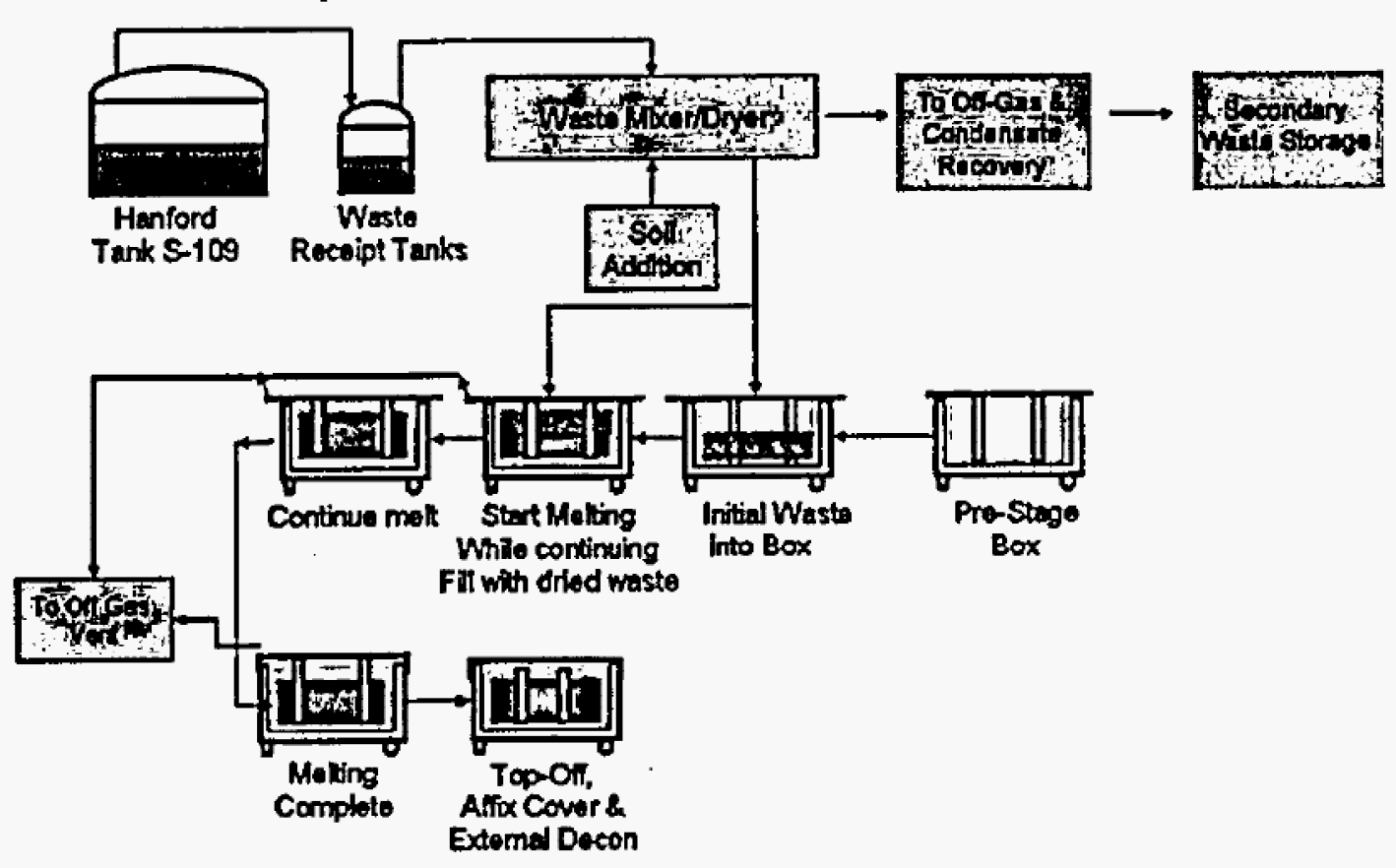

Figure 1. Simplified BV Flow Diagram

\section{Clean Soil System}

The Clean Soil System receives and pneumatically conveys clean soil and glass forming additives to a total of 518 impingement tanks that allow solid materials to be fed by gravity into the waste processing vessels. One tank will feed soil to the Waste Mixer/Dryer, while the remaining three soil tanks feed top-off soil to three separate ports in the ICVTM box. Two additional tanks will feed glass forming additives to the Waste Mixer/Dryer.

\section{Waste Receipt System}

The Waste Receipt System consists of a pump skid and three waste staging tanks. This system will receive, sample, and transport waste from the 24l-S-109 single-shell tank to the Waste Mixer/Dryer and Condensate Recovery Systems. The pump skid will transfer batches of waste from S-109 to one of three waste staging tanks for storage until it is needed for processing. The waste will be sampled to verify that it complies with the DBVS waste feed acceptance criteria.

\section{Waste Mixer/Dryer and Condensate Recovery Systems}

The Waste Mixer/Dryer converts waste liquid into a blended and dried feed product suitable for vitrification. Heat and vacuum will be used to dewater the waste feed/soil 
mixture. During evaporation the Waste Mixer/Dryer will be operated at $60^{\circ} \mathrm{C}$ (or higher) under a vacuum of approximately $660 \mathrm{~mm} \mathrm{Hg}$. The Waste Mixer/Dryer will mix its contents with rotating plows that direct the waste from the ends of the mixer/dryer towards its center. The evaporated water will be pulled through a sintered metal filter (SMF) to remove particulates before the vapors reach the Condensate Recovery System. Particulates captured in the filter will be returned to the dryer drum via back-pulsing of the filters.

Waste drying is a batch process with approximately eight dryer loads required for each ICVTM box. Each dryer load will begin with an initial charge of gravity-conveyed clean soil via the impingement tank located above the drycr. After preheating the soil, waste fced will gradually be added from the waste staging tanks until the correct ratio of wasteto-soil is achieved. Once the entire batch of waste feed is added, the product will be dried to a target water content of about $3 \mathrm{wt} \%$ water. Glass former additives will then be added and mixed with the dryer product. Finally, the Waste Mixer/Dryer will discharge the dried waste to the Dried Waste Handling System through a valve located on the bottom of the dryer, then the batch process will repeat.

\section{Dried Waste IIandling System}

The Dried Waste Handling System transfers the dried waste and soil mixture from the dryer to a waiting ICVTM box. The dried waste will be transferred into a discharge chute at a rate controlled by a rotary valve. As the rotary valve rotates, dried waste will enter a vacuum transfer line where gas velocities will ensure that waste particles remain suspended and transported to one of two Dry Waste Receivers. The dried waste will then be gravity fed from the Dry Waste Receivers into the ICVTM box. Both Dry Waste Receivers will be used to provide an even distribution of dried waste to the two entry points in the ICVTM box. The process is repeated for each dryer batch.

\section{In Container Vitrification ${ }^{\mathrm{TM}}$ System}

The ICV ${ }^{\mathrm{TM}}$ system is designed to receive a waste/soil mixture, contain the bulk vitrification process, and serve as the final disposal container for the product. The ICVTM box will provide primary confinement for dried waste received from the dryer, molten glass during processing, and final waste product.

The soil/waste mix will be melted within the box, using electric power supplied through graphite electrodes. A starter path will be used to initiate the melt. On completion of the melt and after a cooling period, sufficient top-off soil will be added to ensure that the box is at least 90 percent full and a nominal 10 -in. soil layer covers the melt. Once the chutes, electrical connections, ventilation and instrument hamess have been disconnected, the ICVTM box will be moved to the storage pad using an air pallet.

\section{Off-Gas Treatment System}

The OGTS is used to cool, filter, scrub, and chemically treat the various process off-gas and vent streams before exhaust fans discharge them through a monitored exhaust stack to the atmosphere. Off-gas produced during the ICVTM process will be drawn through 
two SMFs connected in series and the collected particulates returned to the dryer by vacuum transfer and re-introduced into the melt process.

Additional air drawn from the waste staging tank vents will be combined with ICVTM process off-gas after the SMFs and fed into the off-gas wet scrubber treatment skid. The gas will be quenched with a caustic solution to cool it before entering the scrubber. This will remove most of the acidic gases (e.g., $\mathrm{NO}_{x}, \mathrm{CO}_{2}$ ) and particulates. After the scrubber, the off-gas will be passed through a mist eliminator, cooled in the condenser, and passed through a second mist eliminator. Ambient air, air from the secondary waste storage tank vents, and air from the dryer off-gas is combined with the scrubbed off-gas, then heated and passed through a series of two high-efficiency particulate air (HEPA) filters.

The filtered off-gas will then be drawn through a high-efficiency gas adsorper (HEGA) filter and polishing filter. The HEGA filter is used to remove residual radioactive iodine and organic carbon from the off-gas stream. The polishing filter will capture filter media particles that may exist in the HEGA filter effluent and will prevent them from entering the selective catalytic reduction (SCR) unit.

After passing through the HEGA filter skid, the off-gas will be mixed with filtered ambient air and drawn into the SCR unit, where it is preheated to bring it to the required operating temperature before entering the SCR reactor. As the off-gas passes through the $\mathrm{SCR}, \mathrm{NO}_{\mathrm{x}}$ will be reacted with ammonia in a catalyst bed to produce water vapor and nitrogen gas. A second catalytic bed will oxidize any remaining $\mathrm{CO}$ to $\mathrm{CO}_{2}$. Hot off-gas from the SCR reactor will pass through the exhaust side of the air-to-air heat exchanger to preheat the incoming off-gas before being discharged through the exhaust stack.

After the stack monitor has sampled and measured the off-gas for the discharge flow, temperature, and contaminants being exhausted to the atmosphere, the treated off-gas will be discharged through the stack by one of two exhaust fans.

\section{Secondary Waste Treatment System}

The Secondary Waste Treatment System provides for the storage of the secondary liquid waste effluents from the dryer condensate and off-gas scrubber solution, and load out of these effluents for transfer to the ETF. Two staging tanks will be provided for interim storage of each of these secondary waste streams, and will be sized such that the secondary waste generated during the production of a single ICVTM box can be contained in two of the tanks (one for dryer condensate and one for off-gas scrubber solution). This approach will provide time for secondary waste sampling prior to transfer to the ETF.

\subsection{Review Process}

The members of the ERP divided into five focus areas:

- mission integration

- overall process flowsheet 
- vitrification and product qualification

- equipment design, including operations and maintenance

- safety.

Each focus area developed lines of inquiry and review plans based on the approved charter. The charter posed five primary questions to be addressed by the ERP.

- Are there any flaws in the current design or operational plans that would prevent the DBVS system from meeting safety or technology demonstration objectives?

- Will the DBVS system meet minimum product quality and demonstration production rate requirements?

- Is the technical basis of the DBVS flow sheet sound?

- Is the DBVS Equipment and Facility design basis adequate to bound the construction and operating costs for the demonstration?

- What are the primary outstanding safety and technical risks/uncertainties for the DBVS?

Relevant DBVS Project management, technical basis, and design documents provided by the project were reviewed. DBVS Project management, technical, and operations staff were then interviewed and provided additional information and clarification of the data originally provided to the team. Since the design and development efforts of the project were ongoing, the DBVS Project team typically provided information that bridged the gap between the released project documents and the current state of the project. In this way the ERP was able to consider the most up-to-date information available for this review. Preliminary draft information developed by the ERP was provided to the project staff for factual accuracy reviews prior to finalizing this report.

Even though the project was in the midst of a major project design completion effort, staff and subcontractors from ORP, CH2M HILL, and AMEC were very open and cooperative. Individuals from the project spent many hours with the ERP and were very responsive to requests for additional information and briefings. Without this cooperation, the ERP would not have been able to complete a quality review in the time available.

\subsection{Review of the Demonstration Bulk Vitrification System Technical Basis}

After the initial document review and onsite meetings, the ERP review subteams prepared an initial set of findings and issues which were reviewed with the project staff for factual accuracy, and in some cases additional clarification. Based on the results of these discussions, issues, areas of concern, and recommendations for improvement were documented in a draft version of this document. This document draft was also provided to the project for factual accuracy review. The document was finalized in September 2006. 
The ERP established four categories for grouping of issues.

- Fatal flaws - the issue will cause failure of the DBVS, and cannot be resolved (no fatal flaws were identified)

- Technical issues - the identified issue will result in a failure of the DBVS to mect established DBVS system, mission, or safety performance requirements unless addressed prior to start of hot operations of the DBVS facility (sce Table 1)

- Areas of concern - the identified concerns may result in a change to design, or may require additional testing to determine if the design is adequate (now or later) (see Table 2)

- Suggested improvements - improvements that the project should consider to improve safety, cost, schedule, or efficiency during the test operations

The report discusses each of the five focus areas, emphasizing specific points within each area including: mission integration of the DBVS Project with the overall completion of the ORP mission and the projects overall risk management approach; flowsheet technical basis; equipment design and specifications review; the sccondary waste system; operations and maintenance approach and impact on design; and finally, the strategy for the development and approval of the facility authorization basis and safety management programs.

The original detailed team reports are included in RPP-31337. These individual team reports include more detailed analysis used to prepare the summary findings of the DBVS Project. The reader is encouraged to review these for a complete discussion of the DBVS flowsheet, equipment design, vitrification system, safety programs, and risk management approach. To avoid misinterpreting what an individual member intended to convey, the write-ups have not been edited for writing style or issue terminology; nor to remove any concerns, regardless of whether they were ultimately classified as Technical Issues or Areas of Concern in the final report.

All of the team leads, together with some of the team members, participated in the categorization of issues in the main body of the report. The main body of this report (RPP-31314) represents a consensus of the ERP. The ERP wishes to emphasize that the contents of RPP-31337 should be considered as working documents of team members.

Tables 1 and 2 indicate the section of the report where the corresponding issue discussion can be found, including potential mitigation for all issues. The order of the issue presentation does not necessarily reflect their relative importance. 
Table 1. DBVS-ERP Technical Issues.

\begin{tabular}{|c|c|c|c|}
\hline $\begin{array}{c}\text { Technical Issue } \\
\#\end{array}$ & Statement of Technical Issue & Report Section & Section No. \\
\hline $\begin{array}{l}\text { Technical Issue } \\
\# 1\end{array}$ & $\begin{array}{l}\text { The DBVS, as currently planned, will not } \\
\text { completely meet all objectives assigned it in } \\
\text { the Justification of Mission Need. }\end{array}$ & Mission & 2.2 \\
\hline $\begin{array}{l}\text { Technical Issue } \\
\# 2\end{array}$ & $\begin{array}{l}\text { Insuflicient integrated system testing prior to } \\
\text { radioactive DBVS operations is planned. }\end{array}$ & Mission & 2.2 \\
\hline $\begin{array}{l}\text { Technical Issue } \\
\# 3\end{array}$ & $\begin{array}{l}\text { There is no present plan for recovery from } \\
\text { off-normal conditions. }\end{array}$ & Flowsheet & 3 \\
\hline $\begin{array}{l}\text { Technical Issue } \\
\# 4\end{array}$ & $\begin{array}{l}\text { The entire DBVS (flowsheet, system design } \\
\text { and operations) is too complex. }\end{array}$ & Flowsheet & 3 \\
\hline $\begin{array}{c}\text { Technical Issue } \\
\# 5\end{array}$ & $\begin{array}{l}\text { The sampling and data acquisition system } \\
\text { (plan and hardware) is not designed to gather } \\
\text { important process and design information. }\end{array}$ & Flowsheet & 3 \\
\hline $\begin{array}{l}\text { Technical Issue } \\
\# 6\end{array}$ & $\begin{array}{l}\text { The soil will not transport as currently } \\
\text { designed. }\end{array}$ & $\begin{array}{l}\text { Equipment Design and } \\
\text { Specification - Solids } \\
\text { Handling }\end{array}$ & 4.3 \\
\hline $\begin{array}{l}\text { Technical Issuc } \\
\# 7\end{array}$ & $\begin{array}{l}\text { The soil will bridge in the hopper and not } \\
\text { feed the dryer. }\end{array}$ & $\begin{array}{l}\text { Equipment Design and } \\
\text { Specification - Solids } \\
\text { Handling }\end{array}$ & 4.3 \\
\hline $\begin{array}{c}\text { Technical Issue } \\
\# 8\end{array}$ & $\begin{array}{l}\text { Because of the uncertainty in the particle } \\
\text { size, moisture content, etc. of the as-dried } \\
\text { material, it is difficult to evaluatc the solids } \\
\text { feed system design. }\end{array}$ & $\begin{array}{l}\text { Equipment Design and } \\
\text { Specification - Solids } \\
\text { Fandling }\end{array}$ & $\overline{4.3}$ \\
\hline $\begin{array}{c}\text { Technical Issue } \\
\# 9\end{array}$ & $\begin{array}{l}\text { There is considerable uncertainty with regard } \\
\text { to the consistency of the dried material and } \\
\text { how it will be controlled. }\end{array}$ & $\begin{array}{l}\text { Equipment Design and } \\
\text { Specification - Mixer/Dryer }\end{array}$ & $\overline{4.3}$ \\
\hline $\begin{array}{c}\text { Technical Issue } \\
\# 10\end{array}$ & $\begin{array}{l}\text { Formation of secondary phases is not } \\
\text { sufficiently understood for reliable process } \\
\text { control. }\end{array}$ & $\begin{array}{l}\text { Equipment Design and } \\
\text { Specification - Vitrification }\end{array}$ & $\overline{4.4}$ \\
\hline $\begin{array}{c}\text { Technical Issue } \\
\# 11\end{array}$ & $\begin{array}{l}\text { Failure to close the technetium mass balance } \\
\text { threatens the viability of bulk vitrification as } \\
\text { a supplemental treatment technology. }\end{array}$ & $\begin{array}{l}\text { Equipment Design and } \\
\text { Specification - Vitrification }\end{array}$ & 4.5 \\
\hline $\begin{array}{c}\text { Technical Issue } \\
\# 12\end{array}$ & $\begin{array}{l}\text { Design criteria for the OGTS have not been } \\
\text { clearly defined. }\end{array}$ & $\begin{array}{l}\text { Equipment Design and } \\
\text { Specification - Orf-Gas }\end{array}$ & 4.5 \\
\hline $\begin{array}{c}\text { Technical Issue } \\
\# 13\end{array}$ & $\begin{array}{l}\text { Testing requirements in equipment } \\
\text { specifications have been inadequately } \\
\text { defined. }\end{array}$ & $\begin{array}{l}\text { Equipment Design and } \\
\text { Specification - Off-Gas }\end{array}$ & $\overline{4.6}$ \\
\hline $\begin{array}{c}\text { Technical Issue } \\
\# 14\end{array}$ & $\begin{array}{l}\text { Potentially large variations in system } \\
\text { component pressure losses and the bysteresis } \\
\text { within the control system could result in } \\
\text { unacceptable response time to achieve } \\
\text { proper flow. }\end{array}$ & $\begin{array}{l}\text { Equipment Design and } \\
\text { Specification - Off-Gas }\end{array}$ & 4.6 \\
\hline $\begin{array}{l}\text { Technical Issue } \\
\text { \#1S }\end{array}$ & $\begin{array}{l}\text { The sintered metal filters will frequently } \\
\text { blind, with a significant risk of release of } \\
\text { contamination. }\end{array}$ & $\begin{array}{l}\text { Equipment Design and } \\
\text { Specification - Off-Gas }\end{array}$ & 4.6 \\
\hline
\end{tabular}


RPP-31314

RPP-31314
\begin{tabular}{|c|l|l|c|}
\hline $\begin{array}{c}\text { Technical Issue } \\
\# 16\end{array}$ & $\begin{array}{l}\text { Testing and safety analysis have not } \\
\text { adequately addressed the ICV } \\
\text { performance for containment of the melt } \\
\text { product, volatile radionuclides, and } \\
\text { generated NO }\end{array}$ & Safely & 7.1 \\
\hline \begin{tabular}{c|c|c|} 
Technical Issue \\
$\# 17$
\end{tabular} & $\begin{array}{l}\text { The safety performance of the DWTS to } \\
\text { contain the dried waste under normal and } \\
\text { accident conditions is not yet fully } \\
\text { understood and defensible. }\end{array}$ & Safety & 7.1 \\
\hline $\begin{array}{c}\text { Technical Issure } \\
\# 18\end{array}$ & $\begin{array}{l}\text { The DBVS Project plans to assign } \\
\text { operational responsibility to a sub-contractor } \\
\text { who has little formal nuclear facility } \\
\text { operating experience. }\end{array}$ & Safety & 7.1 \\
\hline $\begin{array}{c}\text { Technical Issue } \\
\# 19\end{array}$ & $\begin{array}{l}\text { Project uncertainty with various portions of } \\
\text { the unit operations and process chemistry } \\
\text { may heighten safety vulnerability under } \\
\text { abnormal conditions. }\end{array}$ & Safety & 7.1 \\
\hline
\end{tabular}

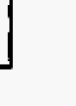


Table 2. DBVS-ERP Areas of Concerm.

\begin{tabular}{|c|c|c|c|}
\hline $\begin{array}{c}\text { Area of } \\
\text { Concern \# }\end{array}$ & Area of Concern & Report Section & Section No. \\
\hline $\begin{array}{c}\text { Area of } \\
\text { Concern } \\
\forall 1\end{array}$ & $\begin{array}{l}\text { Decontaminations calculated for Technetium } \\
\text { and Cesium across the DBVS are } \\
\text { questionably large. }\end{array}$ & Flowsheet & 3 \\
\hline $\begin{array}{c}\text { Area of } \\
\text { Concern } \\
\# 2\end{array}$ & $\begin{array}{l}\text { There is a lack of a basic understanding of } \\
\text { the process chemistry. }\end{array}$ & Flowsheet & 3 \\
\hline $\begin{array}{c}\text { Area of } \\
\text { Concem } \\
\# 3\end{array}$ & $\begin{array}{l}\text { The hydrocyclone may not provide adequate } \\
\text { separation of the smaller particle size solids } \\
\text { expected in the S-109 feed. }\end{array}$ & $\begin{array}{l}\text { Equipment Design and } \\
\text { Specification - Liquid Waste } \\
\text { Feed } \\
\end{array}$ & 4.2 \\
\hline $\begin{array}{c}\text { Area of } \\
\text { Concem } \\
\# 4\end{array}$ & $\begin{array}{l}\text { Given that there is no mechanical agitation in } \\
\text { the DBVS feed tanks, solids could build up } \\
\text { over time }\end{array}$ & $\begin{array}{l}\text { Equipment Design and } \\
\text { Specification - Liquid Waste } \\
\text { Feed }\end{array}$ & 4.2 \\
\hline $\begin{array}{c}\text { Area of } \\
\text { Concern } \\
\# 5\end{array}$ & $\begin{array}{l}\text { The epoxy coating on the waste storage tanks } \\
\text { may not provide adequate corrosion } \\
\text { protection. }\end{array}$ & $\begin{array}{l}\text { Equipment Design and } \\
\text { Specification - Liquid Waste } \\
\text { Feed }\end{array}$ & 4.2 \\
\hline $\begin{array}{c}\text { Area of } \\
\text { Concem } \\
\# 6\end{array}$ & $\begin{array}{l}\text { The batch drying time may exceed the } \\
\text { specified 8-hour duration by as much as } 1- \\
1 / 2 \text { hours. }\end{array}$ & $\begin{array}{l}\text { Equipment Design and } \\
\text { Specification - Mixer/Dryer }\end{array}$ & 4.4 \\
\hline $\begin{array}{c}\text { Area of } \\
\text { Concern } \\
\# 7\end{array}$ & $\begin{array}{l}\text { Temperatures predicted in the mixer/dryer } \\
\text { container during hot weather may not allow } \\
\text { for the proper operation of controls and } \\
\text { equipment. }\end{array}$ & $\begin{array}{l}\text { Equipment Design and } \\
\text { Specification - Mixer/Dryer }\end{array}$ & $\overline{4.4}$ \\
\hline $\begin{array}{c}\text { Area of } \\
\text { Concern } \\
\sharp 8\end{array}$ & $\begin{array}{l}\text { The lack of a validated approach for control } \\
\text { of the } \mathrm{ICV}^{\mathrm{TM}} \text { process puts the project's } \\
\text { ability to proceed to radioactive operations at } \\
\text { risk. }\end{array}$ & $\begin{array}{l}\text { Equipment Design and } \\
\text { Specification - Vitrification }\end{array}$ & 4.5 \\
\hline $\begin{array}{c}\text { Area of } \\
\text { Concern } \\
t 9\end{array}$ & $\begin{array}{l}\text { A feed qualification step is needed as part of } \\
\text { the process control plan. }\end{array}$ & $\begin{array}{l}\text { Equipment Design and } \\
\text { Spccification - Vitrification }\end{array}$ & 4.5 \\
\hline $\begin{array}{c}\text { Area of } \\
\text { Concern } \\
\# 10\end{array}$ & $\begin{array}{l}\text { The lack of prototypic testing prevents the } \\
\text { project from predicting future compliance } \\
\text { from post success. }\end{array}$ & $\begin{array}{l}\text { Equipment Design and } \\
\text { Specification - Vitrification }\end{array}$ & 4.5 \\
\hline $\begin{array}{c}\text { Area of } \\
\text { Concern } \\
\# 11\end{array}$ & $\begin{array}{l}\text { Equipment manufacturers' standard practice } \\
\text { appcars to have taken precedence over code } \\
\text { compliance for the OGTS. }\end{array}$ & $\begin{array}{l}\text { Equipment Design and } \\
\text { Specification - Off-Gas }\end{array}$ & $\overline{4.6}$ \\
\hline $\begin{array}{c}\text { Area of } \\
\text { Concem } \\
\# 12\end{array}$ & $\begin{array}{l}\text { The Wet Scrubber specification does not } \\
\text { require performance testing to demonstrate } \\
\text { the specified removal efficiencies }\end{array}$ & $\begin{array}{l}\text { Equipment Design and } \\
\text { Specification - Off-Gas }\end{array}$ & 4.6 \\
\hline $\begin{array}{c}\text { Area of } \\
\text { Concem } \\
\# 13\end{array}$ & $\begin{array}{l}\text { Design Criteria for the HEPA filters have not } \\
\text { been established. }\end{array}$ & $\begin{array}{l}\text { Equipment Design and } \\
\text { Specification - Off-Gas }\end{array}$ & 4.6 \\
\hline $\begin{array}{c}\text { Area of } \\
\text { Concem } \\
\# 14\end{array}$ & $\begin{array}{l}\text { Carbon cells for HEGA filters do not meet } \\
\text { the required residence time as specified in } \\
\text { the Procurement Specification and ASME } \\
\text { AG-1 Code. }\end{array}$ & $\begin{array}{l}\text { Equipment Design and } \\
\text { Specification - Off-Gas }\end{array}$ & 4.6 \\
\hline $\begin{array}{l}\text { Area of } \\
\text { Concern } \\
\# 15\end{array}$ & $\begin{array}{l}\text { There exists a potential for a charcoal fire } \\
\text { due to concentrations of } \mathrm{NO}_{\mathrm{x}} \text { in the HEGA } \\
\text { skid. }\end{array}$ & $\begin{array}{l}\text { Equipment Design and } \\
\text { Specification - Off-Gas }\end{array}$ & 4.6 \\
\hline
\end{tabular}




\begin{tabular}{|c|c|c|c|}
\hline $\begin{array}{l}\text { Area of } \\
\text { Concem } \\
\# 16\end{array}$ & $\begin{array}{l}\text { The OGTS emergency by-pass filter system } \\
\text { could quickly load with particulate during } \\
\text { upset conditions, resulting in a filter failure } \\
\text { and relcase of contaminants to the } \\
\text { atmospheres. }\end{array}$ & $\begin{array}{l}\text { Equipment Design and } \\
\text { Specification - Off-Gas }\end{array}$ & 4.6 \\
\hline $\begin{array}{c}\text { Area of } \\
\text { Concern } \\
\# 17\end{array}$ & $\begin{array}{l}\text { There appears to be little, if any, design } \\
\text { optimization. }\end{array}$ & $\begin{array}{l}\text { Equipment Design and } \\
\text { Specification-Overall } \\
\text { System Section }\end{array}$ & 4.7 \\
\hline $\begin{array}{l}\text { Area of } \\
\text { Concem } \\
\# 18\end{array}$ & $\begin{array}{l}\text { The scrubber system may not be able to treat } \\
\text { unexpectedly large amounts of gases and } \\
\text { solids, resulting in unacceptable amounts of } \\
\text { material being directed to the ETF }\end{array}$ & Secondary Waste Treatment & 5 \\
\hline $\begin{array}{l}\text { Area of } \\
\text { Concem } \\
\# 19\end{array}$ & $\begin{array}{l}\text { Assumptions about types and amounts of } \\
\text { chemical entering the Secondary Waste } \\
\text { Treatment System }\end{array}$ & Secondary Waste Treatment & 5 \\
\hline $\begin{array}{l}\text { Area of } \\
\text { Concem } \\
\# 20\end{array}$ & $\begin{array}{l}\text { The potential for future use of the DBVS } \\
\text { facility as a single line production facility } \\
\text { and gap filler capability might not be } \\
\text { adequately addressed in the existing design. }\end{array}$ & Operations and Maintenance & 6.2 \\
\hline $\begin{array}{l}\text { Area of } \\
\text { Concem } \\
\# 21\end{array}$ & $\begin{array}{l}\text { An adequate maintenance strategy has not } \\
\text { been developed and incorporated into the } \\
\text { demonstration facility requirements. }\end{array}$ & Operations and Maintenance & 6.2 \\
\hline $\begin{array}{l}\text { Area of } \\
\text { Concem } \\
\# 22\end{array}$ & $\begin{array}{l}\text { Readiness requirements for ultimate hot } \\
\text { operations may be underestimated }\end{array}$ & Operations and Maintena nce & 6.2 \\
\hline $\begin{array}{l}\text { Area of } \\
\text { Concem } \\
\# 23\end{array}$ & $\begin{array}{l}\text { Insufficient consideration to accumulation of } \\
\text { radioactive materials throughout the DBVS } \\
\text { could lead to avoidable radiation exposure } \\
\text { during operations and extra complexity of } \\
\text { the decontamination and decommissioning } \\
\text { effort. }\end{array}$ & Safety & 7.1 \\
\hline $\begin{array}{l}\text { Area of } \\
\text { Concern } \\
\$ 24\end{array}$ & $\begin{array}{l}\text { The large number of TSR-level safety } \\
\text { systems and DBVS-specific administrative } \\
\text { controls may be excessive from the } \\
\text { standpoint of human factors and operational } \\
\text { complexity. }\end{array}$ & Safety & 7.1 \\
\hline $\begin{array}{l}\text { Area of } \\
\text { Concerm } \\
\# 25\end{array}$ & $\begin{array}{l}\text { The documented rationales for the revised } \\
\text { Hazard Categorization are insufficient. }\end{array}$ & Safety & 7.1 \\
\hline $\begin{array}{l}\text { Area of } \\
\text { Concern } \\
\$ 26\end{array}$ & $\begin{array}{l}\text { Safety documentation and analysis does not } \\
\text { provide for a complete accounting of } \\
\text { chemicals used and generated by the DBVS }\end{array}$ & Safety & 7.1 \\
\hline
\end{tabular}




\section{Mission Integration}

Completion of the overall River Protection Project mission requires the treatment of over 53 million gallons of radioactive wastes currently stored in aging single and double shell tanks at the Hanford Site. ORP's plan is to retrieve the wastes and to pretreat as necessary to meet regulatory and performance requirements to produce a HLW feed and a LAW feed. Both of these streams are to be vitrified, with the vitrified $\mathrm{HLW}$ fraction destined for disposal at proposed Yucca Mountain, and the much larger volume of vitrified LAW planned to be disposed of onsite in the IDF. To meet overall schedule objectives to complete the waste treatment mission in 20-25 years, additional LAW treatment capacity is required.

\subsection{Justification of Mission Need}

To a great extent, the overall mission drivers are captured in the Justification of Mission Need (JMN) for the DBVS system, approved in July 2006. The mission need document requires that the DBVS Project:

- Process approximately 190,000 gallons of Tank S-109 waste into fifty 100 metric ton boxes of vitrified product.

- Store and dispose of these boxes at Hanford's Integrated Disposal Facility (IDF)

- Evaluate the waste form characteristics.

- Gather pilot plant operability data, and

- Develop the overall life cycle system performance of bulk vitrification and produce a comparison of the bulk vitrification process to building a second LAW Immobilization facility or other supplemental treatment alternatives as provided in M-62-08.

To fully evaluate the context of meeting thesc primary project objectives it is important to understand the important ORP mission requirements that this project needs to address.

\section{Treatment Strategy Drivers}

Currently, ORP's baseline strategy contemplates deployment of supplemental technologies in two distinct phases. Initially, a 4-line system would be constructed in West Area, along with the needed pretreatment capability. ORP's strategy for utilization of the West Area supplemental treatment is based on the variable nature of Hanford tank waste, which derives from its complex history. A selected subset of tanks has been identified as likely feed to the West Area Production Scale System. These tanks are characterized by their absence of organic complexants and, in general, are lower in cesium concentration due to previous waste processing campaigns done to remove cesium from existing tank wastes. 
A second 4-line system would be built in conjunction with the WTP in East Area. This system would process wastes pretreated in the WTP facility and, in general, will see the same feed materials as the WTP LAW facility. It would allow utilization of the full pretreatment capacity that is designed into the WTP Pretreatment Facility.

ERP considers that the demonstration of the applicability of bulk vitrification as a viable technology for both of these future potential applications is assigned to the DBVS via the JMN.

\section{Pilot Plant Data}

In addition to the JMN's assignment of the development of life-cycle cost and schedule estimates, the full scale production systems require additional design data supporting feed preparation, glass formulation over the range of expected fecds for the mission, and offgas treatment requirements. The JMN assigns the development of the necessary pilot plant data to the DBVS Project.

\section{IIanford Federal Facility Agreement and Consent Order Drivers}

In its current system and baseline lifecycle plans, approximately $40-50 \%$ of the LAW needs to be treated by this additional capacity. DOE and the State of Washington have established a milestone that describes the decision process necessary to select the technology to be utilized for this additional capacity (M-62-08). This milestone describes the information necessary to conduct a comparison between any proposed supplemental treatment and a second WTP-type LAW facility. The information needs include:

- "...The results of all waste form performance data (compared against the performance of borosilicate glass) for all the treatment technologies being considered; performance data will be adequate to make decisions as to the acceptability of any proposed waste form for the waste being considered, and description of the considered treatment technologies (including size, throughput, technical viability, and life cycle cost estimates)

- ...a discussion of Waste Treatment Plant throughput commitments and the realistic potential for enhancing the throughput of currently planned melters, proposed additional melters and potential second generation melters installed at first melter change out

- ... Life-cycle cost estimates that indicate projected funding requirements through completion of the River Protection Project mission, a schedule for construction and operation of proposed new facilities and/or enhancements to the WTP, and projected throughput for each facility..." (Ref Hanford Federal Facility Agreement and Consent Order M-62-08).

According to the DBVS JMN, the DBVS Project is required to develop the necessary information associated with the comparison of supplemental treatment alternatives. 


\subsection{Mission Integration Evaluation}

Given the primary objectives that the DBVS Project has been assigned in the overall ORP strategy, and the more specific objectives directly assigned in the JMN, the ERP expects the following to be addressed by the project in either work completed or planned.

- A production plan to process approximately 190,000 gallons of Tank S-109 waste into approximately fifty 100 metric ton boxes of vitrified product.

- Adequate product qualification and performance assessment to assure that these boxes can be disposed in the IDF facility when it becomes operational.

- A product qualification strategy that addresses the entire range of feeds expected for both the west area and east area systems.

- A pilot plant strategy and plan that addresses all aspects of the data required to design and cost the production scale facility.

- A pilot plant design that complies with DOE nuclear safety requirements including a compliant authorization safety basis and effective safety management program.

- Planned activities to develop all elements of the life cycle comparison, including preliminary production scale system design and cost estimates, performance and cost data for other supplemental technologies, and cost of a second L.AW facility.

As described earlier in the process description, the DBVS Project has aggressively pursued the development and demonstration of the applicability of bulk vitrification as a viable waste treatment technology. However, until recently, the focus of the project has been almost entirely on glass formulation and successive scale up of the melt system to support the initial 50 box operation, with much less attention on scale up and qualification of the remainder of the DBVS. Outside of the melt system, testing has generally involved limited vendor testing or reliance on vendor performance claims as to the applicability of feed preparation, material handling, or off-gas treatment tcchnology and equipment. While successfully cold testing the melt system at full scale, even this testing was conducted without prototypical processes and equipment for feed preparation, mixer/dryer operation, material transfer, and off-gas systems.

Current project plans would not conduct additional prototypical testing of the feed preparation, mixer/dryer system, material transfer, and off-gas systems until the DBVS equipment is installed at the demonstration site. Sub-system and integrated system cold testing would be done with the installed DBVS equipment prior to commencement of a formal operational readiness review and start of hot operations.

The project has conducted a range of glass formulation experiments, and has developed plans to spike the S-109 feed with constituents to represent a wider range of tank compositions. The project has not yet developed plans to address the feed qualification, feed composition and variability of the east area system, including potential flowsheet modifications of the WTP pretreatment system. 
At this stage, a pilot plant testing plan that clearly relates the requirements of the production scale system design back to the DBVS Project is not evident, nor is any such activity planned within the project baseline. Figure 2 demonstrates that, to date, the project has spent a majority of time testing the DBVS system melter with little or no time being spent on testing of the feed and off-gas systems.

Applicability to DBVS

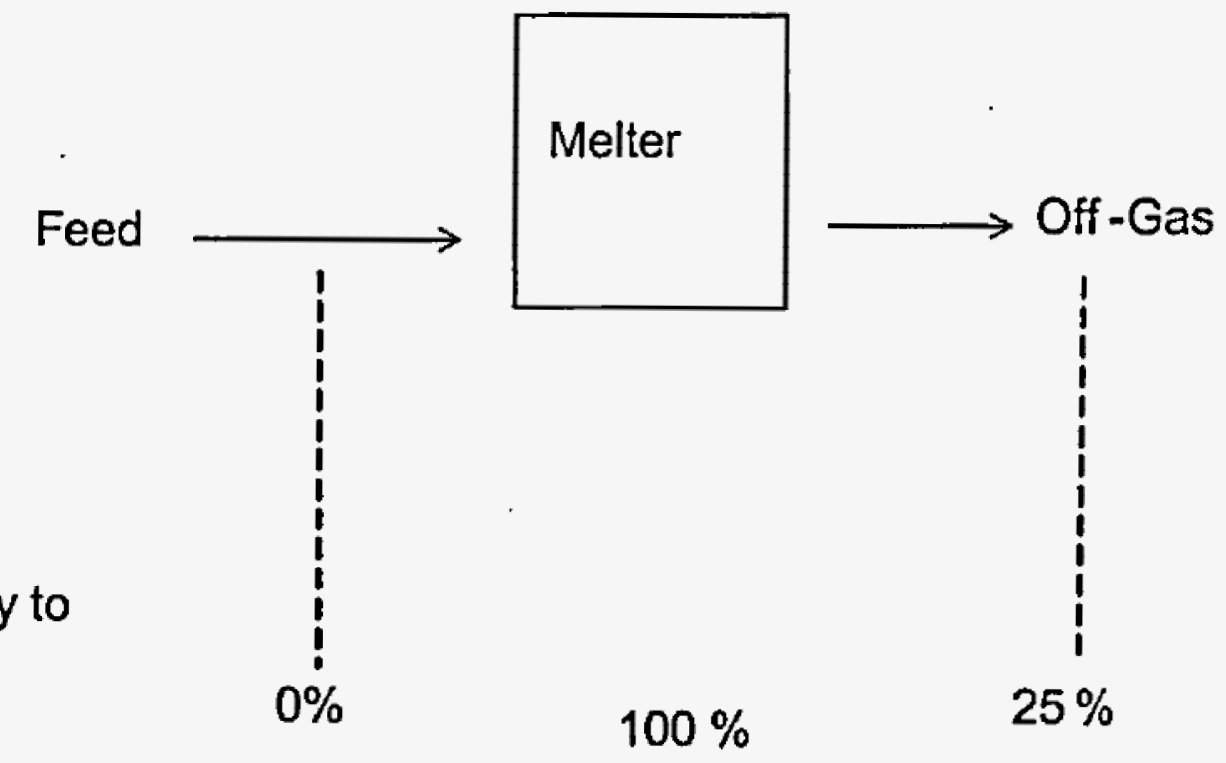

Figure 2. The applicability of the development and demonstration data collected to date in the DBVS design.

Technical Issue \# 1: The DBVS, as currently planned, will not completely meet all objectives assigned it in the Justification of Mission Need

For the first three objectives in the JMN, the project has developed measurable success criteria that will allow an unambiguous determination that the objective has been met. These are carried through into the Integrated Testing and Evaluation Management Plan (ITEMP), so that there is clear evidence that the project will meet the objectives. For the overall life cycle and pilot plant data objectives, there are neither measurable success criteria nor items in the ITEMP that clearly correspond to these objectives.

Potential Mitigation: For collection of data for system design, the project should identify the data it needs and then ensure that such data is generated.

Data needed for decisions that will ultimately be made by DOE presents a much larger problem. DOE should provide the project with specific guidance on the complete set of data needed to make decisions relating to Supplemental Treatment, and the downselection of technology. It does not appear that this has been done, except at a very high level. The project then should convert DOE's data needs into test objectives identified in 
the ITEMP, and would do well to consider formally including them in a Data Quality Objective (DQO).

As an example, the data needed for a decision on the need for supplemental treatment should include a determination of how much of the Hanford LAW can successfully be treated by bulk vitrification. To do this adequately, the project must define the compositional and process operating range over which the technology can be expected to be successful. If the project fails to do this, DOE will not be able to adequately estimate the life-cycle cost of the technology and the number of waste packages that will be produced for comparison with other alternatives.

\section{Technical Issue \# 2: Insufficient integrated system testing prior to radioactive DBVS} operations is planned

The integrated system testing prior to radioactive DBVS operations currently identified in project documentation is limited to 2 cold containers. Neither the scope of the testing nor the objectives of the tests are adequately defined.

There has been no testing of the dryer system (the system that will deliver the dried feed to the melter) nor of the off-gas systern. The latter is particularly of concem because of the system's complexity. Adequate control and understanding of the process must be a prerequisite to beginning radioactive operations; two tests will not provide the information needed for process control. Should process upsets occur during radioactive operations, corrective actions will be much more difficult to correctly formulate and implement than during non-radioactive operations.

A sufficient number of process upsets (particularly if they resulted in release of radioactive materials) could result in substantial delays or in termination of the DBVS Project due to worker exposure and safety, or the perception of an uncontrollable process.

\section{Potential Mitigation:}

- Perform additional testing at both the engineering- and full-scale beyond that currently envisioned for the DBVS prior to radioactive operations is necessary.

- Perform integrated testing of the $\mathrm{ICV}^{\mathrm{TM}}$ process in combination with the feed dryer and OGTS to demonstrate adequate processing of the dried material.

- Address the effect of the dried feed system on bulk vitrification production rate, process stability, salt behavior, pressure stability, and off-gas treatment performance prior to integrated DBVS operations.

- Expand DBVS operations to complete development of integrated system controls, balancing of the off-gas system, and training operators.

- Detail the non-radioactive testing necessary to determine how to operate the DBVS, and the testing to establish that the project is ready to proceed to radioactive operations.

In addition, the operational safety experience and requirements, used at the Tank Farms, should be integrated into the operation of the DBVS Project. 


\subsection{Risk Management}

A key element of this review was an assessment of the adequacy of the risk management process being used for DBVS. This is a critical part of any project in which management defines and quantifies the project risks, decides on actions plans (accept, mitigate, eliminate) for each risk, and assigns the risk to a party for action.

Risk management is a vitally important part of the project management process, as required by DOE Order 413.3-1. Improper risk management will increase the costs, schedule, and performance of the project. For example, if permitting is completed later than scheduled, the costs of the project will increase for several reasons including the need to provide project management support for a longer period of time.

The DBVS risk management process major functions are:

- Risk Identification

- Risk Analysis

- Risk Prioritization

- Risk Response

- Management of Risk Information.

The current DBVS risk management approach is team-based. The team provides data and technical expertise during the conduct of a risk analysis. The function of the risk management team may continue for the life of the program or project. The DBVS project manager implements the requirements of this procedure, assigning and assuring timely participation of required personnel for risk analyses, and adequately planning and budgeting risk management activities in the baseline. The risk management team usually meets once per month to discuss and analyze the status of the project from a risk perspective. One of the key action items of this monthly meeting is to identify a risk owner. This party is delegated responsibility for managing a specific risk event and is responsible for the successful completion of risk mitigation actions.

The ERP evaluated the DBVS Risk Management program and had the following observations.

- The consequence values in the risk management matrix are outdated The consequence values in the risk management matrix are outdated. For instance, risks that could result in a project cost increase of $\$ 1$ million or a schedule delay of 1 month are categorized as "high risk."

Now that the DBVS Project's budget is more than three times its initial budget, a $\$ 1$ million variance is proportionately much smaller. The problem with using the current, outdated set of consequences is that some risks will be rated "high" or 
"very high" when they should not. Such overstating will divert management's
attention away from the most important risks and bog down decision-making.

As a result, the ERP recommends that the DBVS Project team reset the consequence values to higher threshold levels to reflect current project budget and schedule.

- Some risk events may not be recognized and addressed in a timely manner The DBVS Project management tcam uses a risk register to routinely (typically once per month) address individual risks. Once a risk is mitigated, it is transferred to a "closed" list. Risks on that closed list are re-evaluated only when the Risk Management Plan is revised. Revision 0 was published in February 2004, Revision 1 was published seventeen months later (July 2005), and Revision 2 was published four months after that (November 2005). The consequence of untimely review of closed risks is that they may reappear and the project management team would not be aware of their presence. That in tum could have negative cost, schedule, and performance consequences to the project.

The ERP recommends that the DBVS Project review this closed list at least every two months, and that it put previously closed risks back on the active risk register if they have recurred or have increased in significance. 


\section{Process Flowsheet}

Flowsheets are a representation of the entire DBVS process. They include many process steps or features that are common to more than one process subsystem. Flowsheet issues relate to process chemistry; flowsheet presentation; DBVS feed composition; chemistryrelated knowledge required for procedures to recover from process upsets, accidents, or process improvement; DBVS complexity; recovery from off-normal operating conditions; sampling; instrumentation; decontamination factors; and feed characterization.

\section{Technical Issue \# 3: There is no present plan for recovery from off-normal conditions}

The project has not yet addressed the issue of recovery from off-normal operating conditions. There are several circumstances in which off-normal conditions can occur. For example: operators may fail to follow operating instructions leading to process upsets; intractable solids may plug the dryer requiring process shutdown and/or equipment removal; or emergencies that involve releases from the off-gas system containing levels of toxic or radioactive materials that exceed the permit allowances requiring process shutdown.

Failure to provide for recovery from off-normal, emergency, or accident conditions can result in unacceptable expense and delay of the project as wcll as potential harm to plant and offsite personnel. See Safety Technical Issuc \#19 for additional discussion on recovery of off-normal events.

Potential Mitigatation: The ERP recommends the following actions.

- Prepare a computer model of the DBVS that can predict the consequences of offnormal conditions.

- Prepare an action plan with corrective process actions for the off-normal conditions.

- Prepare a manual that covers all of the necessary safety-related reporting and administrative steps.

- Delineate the steps required to record the nature of the occurrence, its consequences and the corrective actions taken.

Technical Issue \# 4: The entire DBVS (flowsheet, system design and operations) is too complex

The ERP believes that the inherent complexity of the processes embodied in the DBVS flowsheet - as manifested in the many interdependent valves, pressures, flowrates, temperatures, and alarms - will make the DBVS very difficult to operate. The DBVS operators will need to be highly skilled and trained to successfully operate the system. There are numerous instances where opening and closing one valve depends on opening and/or closing another valve. These valves in turn control gas pressures and flows 
throughout the entire system. Although this interrelated system of valves appears to be well thought out, it is the sheer complexity of the system that troubles the ERP.

There is a significant potential impact of the DBVS Safety Systems and Administrative Controls on the operability of the system. See Safety Area of Concern \#24 for additional discussion on Technical Safety Requirements.

The complexity of the DBVS is manifested in other ways through the project, for example:

- The project does not appear to have a comprehensive sampling plan for the entire DBVS directed toward establishing the effectiveness of the process controls, providing information necded for construction and operation of a treatment plant, and determining the retention of technetium and cesium as well as vapors and solids throughout the DBVS. Sampling plans developed to date focus on waste form qualification.

Failure to produce and put into usc a comprehensive sampling plan will result in failure to acquire information necessary for DBVS qualification and subsequent construction of an acceptable large-scale plant.

- Because the presentation of the flowsheet is very detailed and presented on scveral pages that require referring back and forth, it is difficult to grasp the flowsheet in its entirety. Although the amount of detail presented is useful to the design engineers and vendors, it is not suitable for use by decision makers and others interested more in understanding the essential features of the DBVS process as they relate to safety, cost, and operating difficulty.

Failure to present an easily understood flowsheet will make it difficult, or impossible, for the non-specialist to evaluate the DBVS process with respect to operability, cost, and suitability relative to alternative technologies.

Potential Mitigation: The ERP recommends the following actions.

- Isolate parts of the system to the extent feasible, such that the extensive interconnections and interdependencies are reduced. This will enhance system operability and maintainability.

- Perform a control optimization exercise to examine the origin of each Technical Safety Requirement (TSR) level control, identify the associated analysis/evaluation conservatisms, determine the sensitivity to the conservatisms, and evaluate the necessity of each of the conservatisms.

- Examine any design attributes that are driving the need for a control and assess whether there are reasonable alternatives that would result in simpler or fewer controls.

- Evaluate the frequency and magnitude of surveillances, readings, recordings, and adjustments in the safety administrative control programs for viability and human factors issues.

- Update the project Human Factors analysis, consistent with the latest control suite. 
- Develop and employ a comprehensive sampling plan for the entire DBVS that will meet the project mission goals.

- Develop a simplified version of the flowsheet for technical communication purposes. It should show schematically on one sheet all the process steps and major equipment pieces (i.e., volumes, masses, concentrations, flowrates, temperatures, and important radionuclides). It should not show valves or other equipment items unless they are essential to understanding operation of the system.

Technical Issue \# 5: The sampling and data acquisition system (plan and hardware) is not designed to gather important process and design information A project objective is to provide the data necessary to evaluate the performance of the waste dryer, material handling system, process vessels, and OGTS. For the " 50 container" campaigns, the sampling plan, to date, is directed at satisfying the DQO compliance/product quality requirement. The number of sampling points and associated devices considered in the current design of the facility are not sufficient to support Research, Development and Demonstration (RD\&D) activities and acquisition of important process knowledge.

Failure to provide for adequate sampling will compromise the ability of the DBVS to accomplish its basic mission - provide the information needed to determine the technical feasibility of the DBVS and to permit a comparison of DBVS with altemative low-level waste treatment technologies.

Potential Mitigation:

Radioactive Waste in the DBVS Receipt Tanks

- Recirculate waste at a higher flow rate.

- Install sampling systems far from any pipe bend.

$I C V^{T M}$ - Core Drilling System

- Obtain truly representative samples of the finished vitrified product.

\section{Off-Gas}

- Sample the off-gas at the stack during operations using continuous monitoring equipment and record sample data. (The ERP notes that the current design does not include any samplers that could support:1) identification of the chemical reactions occurring, 2) tracking of the entrainment/accumulations of radionuclides, and 3 ) determination of all the needs for a production facility (per DQO Section 4.1.3.3).

\section{Secondary Liquid Waste}

- Samples are manually taken from the four liquid waste tanks by dipping a 1-liter sample bottle through a sample port located atop each tank. That is acceptable for a test facility but the ERP believes that a better system should be used for a future production facility. 


\section{Instrumentation}

- When a comprehensive sampling plan is available, an evaluation should be madc of the current instrumentation design to determine if this instrumentation is sufficient to support RD\&D type test campaigns. In addition, a complete instrumentation and control performance evaluation is needed to ensure that the control of the DBVS system can be maintained.

Area of Concern \# 1: Decontamination calculated for Technetium and Cesium across the DBVS are questionably large

Calculating decontamination factors for individual separation steps, when combined to obtain an overall system decontamination of the waste streams for technetium and cesium, may yield factors that are unexpectedly large. The types of relatively simple decontamination process steps used in the DBVS are not usually capable of achieving the overall degree of decontamination cited $\left(10^{5}\right.$ to $\left.10^{6}\right)$ for vapors, gases, and other physical forms that may be expected for technetium and cesium in some parts of the system.

An unrealistic assessment of decontamination factors, especially if they are questionably large, can Icad to potential radiation overexposures and radioactivity releases to the environment that are neither ALARA (as low as reasonably achievable) nor within state or Federal acceptance limits.

\section{Potential Mitigation:}

- Re-examine the decontamination factors for the various process steps in order to ensure that they are valid and that the method of combining them to obtain an overall system decontamination factor is valid. This can be accomplished by:

- Sampling the filter both before and after filtration to determine if the decontamination factors are valid.

- Obtain material balances for technetium and cesium across the DBVS.

\section{Area of Concern \# 2: There is a lack of a basic understanding of the process} chemistry Chemical data have not yet been obtained to enable an understanding of chemicallybased observations during tests. Exceptions are the chemical analyses performed on the vitrified mass itself.

The DBVS tests have been conducted almost exclusively in connection with the behavior of the $\mathrm{ICV}^{\mathrm{TM}}$ box and its contents, with very little attention paid to understanding the chemistry of what is happening in the remaining process steps. To date, nearly all of the experimental tests have addressed the process tests runs phenomenologically and descriptively rather than chemically.

If the system experiences off-normal conditions that lead to unanticipated behavior of technetium and/or cesium it will be very difficult to know what corrective actions to take in the absence of chemical knowledge about the chemical species involved. Likewise, it will be difficult to know how to improve the process in the absence of chemical knowledge. 
The chemical species of technetium as it moves through the DBVS has not been experimentally determined, but are inferred from known technetium chemistry. The identity of the chemical species of technetium in the glass is unknown except by inference. There is experimental evidence that technetium concentrates at the melt/mullite box interface. It has been speculated that sulfate ion plays a role in this behavior. However, there is no analytical data to support that speculation. It is believed that technetium leaving the $\mathrm{ICV}^{\mathrm{TM}}$ will deposit on the steel mesh filters and on the system piping, but there is no experimental evidence to determine whether it deposits as $\mathrm{Tc}_{2} \mathrm{O}_{7}$, as an adhered (and unknown) chemical species on the piping, or as a deposit on the large mass of solids that are presumed to be trapped by the filters. There is no experimental information on the nature of the technetium presumed to be trapped in the off-gas scrubber. Similar statements are true for the nature and behavior of cesium. Failure to understand the chemistry underlying observations poses the risk that when there is an unexpected occurrence of a chemical nature (or an accident), there is likely to be little or no understanding of the underlying reasons for the occurrence. Consequently, there will be no rational basis upon which to base corrective or recovery actions. Furthermore, there will be no basis on which to make chemistry-related process improvements.

Potential Mitigation: The ERP recommends that additional chemical information be obtained both by sampling to obtain chemical information during and after DBVS test runs and by laboratory experiments. In all cases, acquisition of chemical data should be driven by a need to understand observations made during the test runs and have the goal of furthering understanding of process chemistry as it relates to meeting DBVS mission goals.

\section{Suggested Improvement: The DBVS Project should consider additional characterization with regard to organic materials likely to be present in the waste feed \\ Knowledge of the baseline chemical and radionuclide composition of waste transferred from Tank S-109 to DBVS relies on the S-109 Best-Basis Inventory obtained from the Tank Waste Information Network System and on analyses of samples taken during the engineering and full-scale vitrification tests.}

There has not been enough attention paid to the presence of organic compounds in some of the melter feeds, especially in real tank wastes that are candidates to be treated by the full scale process facility other than S-109. The ERP questions the use of allyl alcohol as a surrogate for all the organic compounds that will be present. Organic compounds present in tank wastes other than those from S-109 will have very different compositions from the wastes in S-109. Some of compounds will decompose into inorganic compounds that may enter the off-gas system, depositing on the filters and recycling back into the melter (e.g., phosphates and sulfates). In addition, there will be complexants such as ethylene diamine tetraacetic acid (EDTA) and similar compounds present in some of the wastes. Decomposition products of these compounds will contribute to the composition of the gases and vapors in the plenum above the melter and change the 
chemistry and redox potential in that region. This could affect the chemistry of technetium as well as other multi-valent elements (e.g., ruthenium, which although mostly non-radioactive, will be present in significant amounts).

Failure to adequately consider the range of organic compounds present in the tank wastes processed in the DBVS tests, and perhaps subsequently in a plant based on DBVS technology, can lead to plant inoperability and unanticipated costs.

Potential Mitigation: Testing a representative suite of organic compounds found in waste tanks other than S-109 to determine decomposition products under DBVS operating conditions, especially as they occur in the vitrifier and in the $\mathrm{ICV}^{\mathrm{TM}}$ plenum, and evaluate their potential to interfere with normal DBVS operation would mitigate these concerns. 


\section{Equipment Design and Specification}

\subsection{Systematic Approach}

The DBVS was broken down into its primary systems and a lead appointed for each system. The primary systems are:

- Liquid Waste Feed System

- Solids Handling and Feed to Dryer

- Mixer/Dryer System

- Vitrification System

- Off-Gas System

- Secondary Wastes

The approach to the revicw of each system was identical. Each system was broken down into sub systems and components for initial analysis. Having been analyzed at the subsystem/component level they were then reassembled into the major systems and the functionality of each complete system was then assessed.

In addition to analyzing each major system, ERP also reviewed the overall process and plant design for functionality and did an operability and maintainability review.

\subsection{Liquid Waste Feed Systems}

The DBVS Liquid Waste Feed System analysis comprises S-109 tank retrieval, solids removal by hydrocyclone, hose-in-hose transfer from the S-109 to the DBVS facility, receipt and storage tanks, sampling systems, and recirculating systems. CH2M HILL has extensive experience in retrieving and transferring tank farm wastes. Sample analyses of the S-109 liquors taken several years ago indicate there is nothing in the S-109 wastes that should cause problems during retrieval and transfer. The waste retrieved will be sent through a transfer pit containing a hydrocyclone which is designed to remove solids $\mathbf{5 0}$ micron or greater. These solids will be re-routed back to S-109. The liquid waste will be transferred by hose-in-hose transfer line to one of 3 carbon steel waste receipt tanks. These tanks are horizontally mounted, cylindrical tanks with an operating capacity of approximately 15,000 gallons. The inlet to these tanks is equipped with a sampling system. The waste receipt tanks include a hose-in-hose recirculation loop which discharges to the mixer/dryer, this recirculation loop is equipped with a second sampling system. The 3 pack design is such that one tank can be feeding, while a second is undergoing chemical and radionuclide analysis and a third tank is acting as a receiver tank for waste from S-109.

A key feature of the waste receipt system is to ensure that the waste is thoroughly mixed prior to feeding the dryer. Mixing of the wastes is accomplished through the recirculation pump and a hose-in-hose piping loop. Waste is removed from the tank via a nozzle at the lower end of the tank and routed to a return inlet nozzle at the opposite end. 
During this recirculation, up to three samples will be taken to ensure that the tank is mixed. The recirculation loop is also used to feed the dryer. This allows the tank undergoing chemical/radiological analysis to not become agitated. When it becomes the feed tank for the dryer it is fed to the dryer without further sampling.

Area of Concern \# 3: The hydrocyclone may not provide adequate separation of the smaller particle size solids expected in the S-109 feed

The current design includes a hydrocyclone for solids separation which is designed to remove all fines above 50 microns. It is intended that this will be used to meet the DBVS feed specification level of $3 \% \max$ solids. The particle size distribution of the sludges shows an average particle size of 10 microns, well below the 50 micron particle removal level of the hydrocyclone. The concerm is that sludge fines will be carried and will settle out in the waste receipt tanks. The operating design is to retrieve waste from S-109 above the sludge layer with the intention that sludge fines will not be picked up with the waste. However, the defense in depth argument which is part of the safety case relies on efficient operation of the solids separation device and clearly the hydrocyclone will not perform the required duty.

Potential Mitigation: The ERP recommends that either the technical case be made that solid fines cannot be picked up in S-109 and transferred to DBVS or that the hydrocyclone be replaced by a more efficient filter.

Area of Concern \# 4: Given that there is no mechanical agitation in the DBVS feed tanks, solids could build up over time (assumes the solids/liquid separation step is not adequate)

The waste reccipt tanks are horizontal ( $15 \mathrm{ft}$ long by $5 \mathrm{f}$ diameter) and are not equipped with mechanical agitation. The only mixing that may occur relies on agitation as a consequence of the recirculation loop. ERP is concemed that there will be "dead spots" in the tank, particularly by the inlet nozzle, this is further exacerbated by the cyclical approach to mixing (i.e., only 1 tank out of 3 being mixed at any one time) and the fact that waste feed has been standing for several hours without agitation before it is fed to the dryer and the waste is not sampled again before being fed to the dryer. This would probably not be an issue if there were confidence that there was no solids carryover to the waste receipt tanks. But as this is not so (see issue above) the concern remains for gradual solids build up in the waste receipt tanks.

Potential Mitigation: The ERP recommends that solids separation be improved (see recommendation against Area of Concern 3 above) such that solids do not enter the receipt tanks and/or the project enhance the waste receipt system design to include mixing in the receipt vessels. Also see suggested improvement 2.

Area of Concern \# 5: The epoxy coating on the waste storage tanks may not provide adequate corrosion protection

The receipt tanks are SA $516 \mathrm{G} 60$ carbon steel, coated with a general purpose epoxy to provide a corrosion barrier. The information provided by the coating vendor suggests that the coating is resistant to materials having a pH value between 2 and 12 . The initial 
waste feeds will likely have a $\mathrm{pH}$ in the 13 to 14 range. If the protective coating fails the waste comes in contact with the carbon steel wall of the vessel. The composition of the waste feed to DBVS will have a nitrate concentration of $\sim 5 \mathrm{M}$ with free hydroxide around $0.1 \mathrm{M}-0.2 \mathrm{M}$ at the onset of start-up with associated nitrite concentrations on the order of $0.1 \mathrm{M}$. However, as waste is retrieved form the tanks the hydroxide levels will drop. The waste is outside of the double-shell tank corrosion specification and could lead to stress corrosion cracking and pitting in the receipt tanks.

Potential Mitigation: The ERP recommends that the project validate that this isn't an issue or change the coating requirements to withstand the environment in the vessel.

Suggested Improvement: The DBVS Project should consider designing separate delivery systems for agitation of the tank during characterization, agitation of the tank during dryer feeding, and delivery to the waste sampler system The liquid waste handling system includes a recirculation/waste delivery system which serves three purposes at different times in the operational cycle (i.e., agitating the tank during characterization, agitating the tank during dryer feeding, and serving as the waste sampler system). While this is a very compact and efficient design, the problem is that it can only perform one function at a time. With the unknown duration to mix the tank contents and delays trying to feed the dryer from one tank whilst mixing another tank for characterization it is recommended that the project usc separate systems for each function.

\section{Suggested Improvement: The DBVS Project should consider a common design/supplier for the two sampler systems}

The liquid feed system has two sampling systems both designed to take samples which will be analyzed for process control, material accountancy. Although the two samplers are located close to each other and are sampling the same materials they are different designs and from two different manufacturers. The project should consider a common design/supplier for these sample systems.

\subsection{Solids Handling Systems}

Pneumatic transport of solids is utilized in two primary systems within the DBVS process: (1) feeds to the melter/dryer and (2) feeds from the melter/dryer to the $I C V^{T M}$. First, soil and glass forming chemicals are transported to and collected in specially designed cyclone "impingement tanks." Soil is mechanically discharged from the storage tanks into the mixer/dryer system for drying prior to the addition of glass formers. The blended, dried solids are periodically discharged from the dryer and pneumatically transported to the melt box for incorporation into the desired glass product.

Technical Issue \# 6: The soil will not transport as currently designed Soil is delivered via trucks provided with conventional aerated hoppers and a rearmounted blower. The soil will be conveyed pneumatically in dilute phase transport to the clean soil impingement tank located atop the dryer. 
The vendor used a non-standard design procedure that makes a number of assumptions regarding soil density, particle size distribution, and the resultant "pickup velocity". The vendor procedure does not account for the significant impact that soil moisture and local variability of soil properties will have on the ability to transfer material, nor does the vendor rcquire or request soil sampling and testing which is typically necessary to finalize the design of pneumatic transfer systems. The various factors used in this calculation are apparently based on the vendor's judgment, with no reference basis cited, nor validation by material testing over the ranges of expected operations.

Potential Mitigation: Hopper flow tests (either full scale or appropriately scaled) should be conducted with soils of varying moisture content, particle shape factors determined, and assure that the vendor's performance curves are validated to establish confidence in equipment specifications. Bounding limits specified for moisture content and maximum sieved particle size of the soil delivered to DBVS are necessary to assure reliable opcration of the feed system.

Technical Issue \# 7: The soil will bridge in the hopper and not feed the dryer Each accumulated batch of soil is anticipated to empty by gravity flow into the dryer upon opening the valve at the base of the impingement tank's hopper. This was not experimentally tested and was based solely on predictive correlations of compaction. This assertion does not take into consideration the significant role that moisture content can play in causing bridging and will result in difficulties in operation of a hopper delivery system.

Normally, actual flow tests over a range of moisture contents would be conducted to establish confidence in system design; these were not carried out in this instance. The lack of real test data and control of moisture content causes a major concern regarding the likelihood of the soil bridging in the feed hopper.

In addition to the possible difficulty of damp soil bridging above the tank discharge valve, there exists the potential of particle re-entrainment in the impingement tank's exiting air vortex exists. Normal industry practice is to never allow collected solids to accumulate within the body of a cyclone even if the level is predicted to be well below the exiting gas" "natural vortex length". The designed impingement tank does not follow the conventional concepts of a "filter-receiver".

Potential Mitigation: The ERP recommends that a few simple "bridging " and minimum conveying velocity tests be conducted as a function of moisture content, as well as a scaled filled cyclone re-entrainment observation.

Technical Issue \# 8: Because of the uncertainty in the particle size, moisture content, etc. of the as-dried material, it is difficult to evaluate the solids feed system design In the current design, the dried free-flowing waste discharges by gravity flow into a rotary valve and drops into a pneumatic conveying line intended to convey the waste in a dense phase manner into batch-accumulating impingement vessels atop the melter. The 
vendor defined line size and blower specifications for their bid package. The vendor based his calculations on the fresh soil with a mean particle diameter of 200 microns (of interest is that this is a different assumption than that used in the previous soil transport calculations).

Since the pneumatic transfer of solids has a significant element of art associated with the design of components, it is essential to work with an experienced vendor. Without proper test data, it is difficult to determine if the dried, blended product can be easily transferred or if it will be problematic. The assumption of dense phase conveying adds significant complexity, particularly in the event of an upset (i.e., if the system loses power during transfer and the material settles in the pipe it will be virtually impossible to re-start as designed).

Potential Mitigation: The ERP recommends that the DBVS Project consider specialized systems with controlled and regulated gas injection or bypass pipeline technology for materials that do not have a natural tendency for dense phase conveying. A proper purge control system may need to be designed and tested to avoid pipeline blockages.

\subsection{Mixer/Dryer}

The system reviewed comprised the mixer/dryer; all connected liquid and solid feeds immediately adjacent to the dryer, including controls; the solids transfer system as it leaves the drycr; off-gas components, including the SMF, condenser, and condensate tank; HVAC system for the dryer and condenser boxes; the boiler for the dryer; and the chiller for the condenser.

CH2M HILL already has the production scale dryer planned for installation in DBVS. It was originally purchased for the Transuranic and Mixed Waste (TRUM) packaging project and was transferred to DBVS when work on the TRUM project was suspended.

The dryer has a 10,000 liter capacity and a series of plows powered by a hydraulic drive. The dryer is designed to operate in a batch mode as follows: feed $6,750 \mathrm{lbs}$ of $5 \%$ moisture soil from the Hanford site; heat soil to operating temperature of about 140 $160^{\circ} \mathrm{F}$; add 1,625 gallons of waste ( $-5 \mathrm{M}$ Na solution, $\sim 66 \%$ water, $\left.10.8 \mathrm{lb} / \mathrm{gal}\right)$ in small batches over an 8 hour period. The target is to maintain a 1-3\% moisture content during dryer operation which helps to eliminate build up on the dryer walls and keeps the plow drive motor power relatively constant. At the end of the 8 hour drying cycle, 1,268 lbs of zircon sand and $582 \mathrm{lbs}$ of boron oxide are added and the mix is blended for 30 minutes. Over the next 8 hours, the mix is then fed through a pneumatic conveying system to the $\mathrm{ICV}^{\mathrm{TM}}$ where it is melted into one of the $\mathrm{ICV}^{\mathrm{TM}}$ batches.

The dryer is housed inside a containment box which is locally cooled. It is steam heated from a local boiler and the off-gas system contains a condenser sized to remove the excess water $(-1500 \mathrm{lbs} / \mathrm{hr})$. 
The mixer/dryer is a batch process staged between two continuous processes and as such its performance is critical to the DBVS plant throughput. The consistency of the dried product and the ability to feed the ICV ${ }^{\mathrm{TM}}$ are again critical (i.e., too "wet" and there is a danger of agglomeration and jamming in the ICV ${ }^{\mathrm{TM}}$ feed system, too dry and there is potential for significant dust creation causing problems in the off-gas system). The major concerns relating to the dryer come from the lack of development data to underpin the dryer design and process parameters. All of the full scale tests at Horn Rapids to date have used a solid feed, so none of these have any relevance to the dryer performance. There have been some bench scale testing to establish the drying characteristics of the material and there have been approximately 20 tests done using the 130 liter dryer. However, of the 20 tests, only one of them (nun 2-2 DBVS, TRPT.002), is relevant to the currently proposed method of drying and this has been used as the basis for the full scale dryer design and specification.

Technical Issue \# 9: There is considerable uncertainty with regard to the consistency of the dried material and how it will be controlled

The current control philosophy is to use the temperature of the solids bed as an indicator of the moisture content, and the current specification is to maintain the moisture content of the bed at 3-5\%. Unfortunately test $2-2$ did not support this approach since the moisture content cyclically varied round the $0.5 \%$ level throughout the test while the bed temperature steadily declined from $200^{\circ} \mathrm{F}$ down to $140^{\circ} \mathrm{F}$. The material consistency varies with the moisture content, and in test 2-2 some egg size agglomerates were found in the dried material. If the material is too dry it will increase the dust loading in the offgas system, too moist and it will agglomerate in the dryer and be difficult to discharge and transport.

Potential Mitigation: The ERP recommends that a solid approach to dryer control be considered to ensure that material is successfully transported and reliable fed to the $\mathrm{ICV}^{\mathrm{TM}}$. This is a major issue which needs additional testing and development using the 130L-sized dryer with S-109 liquid feed simulant, actual Hanford soil and Becker plows to:

- Verify that a product moisture level of between 1 and $3 \%$ can be maintained by controlling the bed temperature;

- Investigate the potential for operating the dryer in a continuous liquid and solids feed and solids discharge mode;

- Verify that the substitution of zircon sand for zirconium dioxide does not materially change the solids product characteristics;

- Generate data for the design and operation of the SMFs and for the vacuum pump and condenser.

- Determine the variability of the basic data used in sizing the full scale unit.

- Determine effects of Becker blades and their wear rates.

- Determine if large agglomerates will be formed and determine what effect they will have on the pneumatic conveying system. 
Area of Concern \# 6: The batch drying time may exceed the specified 8-hour duration by as much as $1-1 / 2$ hours

Scale up of the results of Test 2-2 indicates that to process a complete batch would require 9.5 hours versus the 8 hours in the specification (i.e., the dryer is undersized by $\sim 20 \%$ ). However, this test resulted in moisture content $0.5 \%$ versus the $1-3 \%$ specified. If a higher moisture content were achieved this should result in a shorter drying time. The review team feels that this is achievable and for this reason this is flagged as an area of concern, rather than a technical issue, but it needs validating in future tests.

Potential Mitigation: This will be covered in the tests recommended against Technical Issuc 9.

Area of Concern \# 7: Temperatures predicted in the mixer/dryer container during hot weather may not allow for the proper operation of controls and equipment The mixer/dryer, hydraulics, and chiller are all contained within a closed container. While maintaining reasonable (currently specified as $85^{\circ} \mathrm{F}$ ) temperatures is not too important for personnel access due to the expected requirements for limited access, the proper operation of controls and equipment will require limited temperatures. It is calculated that in the summer the temperature inside the container could reach $95^{\circ} \mathrm{F}$.

Potential Mitigation: The ERP recommends that the project decide if this is acceptable or if additional cooling needs to be provided.

Suggested Improvement: The DBVS Project should investigate the options/ benefits of operating the dryer in a continuous mode

The logic of having a batch process in the middle of what is basically a continuous process is not ideal. It is recommended that the project investigate the options/ benefits of operating the dryer in a continuous mode and see how this affects the overall DBVS process.

The project may need to consider alternative design approaches to meet desired production rates. To avoid back-mixing of incompletely dried waste, and to increase plant production rate, a continuous feed to the dryer should be followed by a continuously moving path through the dryer. To achieve an acceptable path length requires maximum heated surface area at as high a surface temperature as admissible, and as shallow a layer of agitated soil as feasible. One dryer design appears promising. The design incorporates heated paddles that will increase the available heated surface and the rate of heat transfer.

While no parametric dryer design study has been completed, experience suggests that an optimal system would result in specification of two or more small diameter, dual shaft dryers operating in parallel, each with an externally direct fired heated wall and provision for a gentle through-flow of air to carry off water vapor and reduce its partial pressure within the dryer. All paddles would be unidirectional thus eliminating the "kneading" action of the present design, which is likely the source of observed "balls" in the waste stream for some operational modes. The necessary residence time for complete drying of 
the waste can be achieved by the designed pitch of the paddles and the rotational speed of the shaft, with a shallow slope of the dryer from feed end to discharge end. Two or more small dryers operating in parallel afford continuity in processing, albeit at a reduced rate, in the event of an inadvertent failure somewhere in the system. Smaller units would afford full scale testing before installation, and would simplify replacement if ever necessary at a later date.

\section{Suggested Improvement: The DBVS Project should consider mounting the dryer} above the mixer in order to simplify the fced systems

The current dryer product feed to the mixer is extremely complex and has major issues (sce comments in section on solids handling). If the dryer were mounted above the mixer it is felt that the feed systems could be significantly simplified.

Suggested Improvement: The DBVS Project should determine the disposal path for decontamination soil prior to startup

The route for disposal of soil uscd to decontaminate the dryer before maintenance should be determined so that an acceptable method for disposal is defined before operation begins.

\subsection{Melter System and Vitrification Process}

The $\mathrm{ICV}^{\mathrm{TM}}$ container is based on the standard $50 \mathrm{cu}$. yd. roll-off container. Within the container's mctal shell, the wall is composed of 6 in. of refractory sand behind 6 in. of castable refractory block (CRB). The floor is composed of an 8-in. layer of refractory sand interspcrsed with CRB bricks that support a layer of CRB panels. Two cylindrical graphite electrodes are extended into the container from lid access ports to provide the electrical power necded for converting the dried feed to a vitrcous product.

To prepare the container for processing, an electrical "starter path" is laid on the bottom CRB pancls. The starter path consists of a conductive graphite-soil mixture to provide a conductive electric path between the graphite electrodes once they are installed. The area of the container bottom not covered by the graphite/soil starter path mixture is covcred to an equivalent depth with iron-free glass frit.

The ICV ${ }^{\mathrm{TM}}$ lid provides limited containment of the process gases and feed particles from the environment, and connections to the feed and off-gas systems. A refractory fiber blanket gasket provides limited in leakage protection. However, the gasket does not provide a leak-tight seal. The ICV ${ }^{\mathrm{TM}}$ lid remains with the $\mathrm{ICV}^{\mathrm{TM}}$ container after processing and is sent as part of the disposal package to the IDF. The lid is not insulated, relying on air flow into the plenum space and the insulating nature of the feed pile to avoid excessive warping duc to high temperatures.

Vitrification of the dried waste-soil mixture is based on a "bottom-up" melting procedure. To begin, two batches of the dried feed are discharged into the container. Power is then applied to the electrodes causing heat up of the starter path material via joule heating. The heat propagates outward and upward eventually melting the adjacent soil/waste 
mixture, effectively establishing an electrically conductive molten mass. Six additional dricd soil/waste batches are subsequently fed onto the surface of, and eventually incorporated into, the melt pool.

As each batch of dried feed mixture is heated, ionic salts in the waste generally melt before any of the other feed constituents. These salts tend to separate from the rest of the feed due to surface forces, and float on the melt surface. It has been observed that the technetium in the waste preferentially partitions into the molten salt phase, which upon cooling is primarily a soluble sodium salt (sulfate and halides). Thus, in the final DBVS product, technetium in the salt phase will be soluble, and available for release from the $\mathrm{ICV}^{\mathrm{TM}}$ container in the IDF.

The project plans to maintain a "cold cap" on top of the molten glass - a pile of unmelted dried feed mixture of sufficient thickness to minimize the loss of volatile species and heat, and to kecp the ICV ${ }^{\mathrm{TM}}$ container's plenum space cool. After the final waste feed has been added to the melter, a mixture of clean soil and glass formers is added. This matcrial is intended to assure incorporation of all of the waste (including any separated salts) in the glass product.

Particulate, vapor, and gaseous species produced by the decomposition and reaction of the wastes are carried into the OGTS. The container's plenum is maintained at a slight negative pressure relative to ambient. However, in the event of a process upset, pressurization of the plenum and release of contamination and gaseous effluents (e.g., $\mathrm{NO}_{\mathrm{x}}$ ) is possible, and has been observed in largc-scale testing.

After the ICV ${ }^{\mathrm{TM}}$ container has cooled sufficiently, the lid connections are unmade and the penetrations are sealed. Once cooled, one or more core samples are taken from the container for product characterization. If these samples conform to the IDF's requirements, the ICV ${ }^{\mathrm{TM}}$ containers will then be transferred to the IDF for disposal.

\section{Technical Issue \# 10: Formation of secondary phases is not sufficiently understood} for reliable process control

In the large-scale testing performed by the project, both iron metal and molten salt phases have formed. Both of these phases can penetrate the refractory and threaten the integrity of the $\mathrm{ICV}^{\mathrm{TM}}$ container. Technetium partitions, preferentially, into both of these phases. Technetium is believed to be more readily released from the iron phase than from the glass. Technetium in the salt phase is soluble, and thus definitely more readily released. Molten salts can also volatilize, and condense on the relatively cooler surfaces of the lid. In addition to the product implications, the salt can be highly corrosive, and increases the particulate burden on the OGTS.

The project has taken several steps to limit the formation of a separate iron phase. As a result, the amount observed has been reduced from hundreds of pounds of metal to less than one. However, since several process changes have been made at the same time, the project does not know the relative effectiveness of any of the changes made. Thus, it will be difficult to translate this success into reliable process control. 
The project has not demonstrated that it can control the amount of molten salt formed. Only limited $\mathrm{ICV}^{\mathrm{TM}}$ testing has been done with a chemically accurate S-109 simulant, and none with other compositions intended for use during DBVS radioactive operations. While the fraction of a technetium surrogate incorporated into the glass almost doubled in the most recent test (FS-38C), the reason for this success - the compositional and operational factors that affect the fraction of non-vitrified soluble technetium - are not completely understood. Further, this success is relative, since only about three-fourths of the technetium surrogate fed to the ICV ${ }^{T M}$ was found in the glass. As a result, appropriate control measures to ensure the production of compliant products have not yct been identified.

Potential Mitigation: The ERP recommends that the DBVS Project carry out an experimental program designed to provide the data needed for process control. This would include small-scale experiments to elucidate mechanisms and explore potential improvements, and larger-scale tests (engineering and full-scale) to develop definite control measures and limits and to demonstrate effective and reliable process control. It should be noted that if one-fourth of the technetium were present in a soluble form, it is not clear that the containcrs produced by a production bulk vitrification system would meet IDF disposal requirements. The cxperimental program to develop control measures should also look at methods, both physical and chemical, to retard the mobility of the technetium if present in a soluble form. For example, fly ash has been shown to reduce the tcchnctium to an insoluble form. Thus, fly ash could be added to the sand around the CRB (or be a part of the aggregate used to make the CRB), and thus limit the mobility of any soluble technetium not incorporated into the glass.

Technical Issue \# 11: Failure to close the Technetium mass balance threatens the viability of bulk vitrification as a supplemental treatment technology

In all of the tests performed to date, a significant fraction (at least $24 \%$ ) of the technetium (or technetium surrogate) fed to the process has not been accounted for in product analyses. The assumption being used for IDF performance modeling is that the unaccounted fraction is present in a soluble form. At this level, while the 50 containers produced by the DBVS would most likely mect IDF disposal requirements, those produced by a production bulk vitrification system most likely would not. This would mean that the DBVS would fulfill its objective to dispose of its product in the IDF, but it would do it in such a way that bulk vitrification would be rendered untenable as a supplement to the WTP.

Potential Mitigation: The project should better quantify this unaccounted for fraction. Testing at an engineering scale with technetium and at full scale with a technetium surrogate would both be advisable, given the importance of the issue. ${ }^{1}$ Test objectives should be defined with numerical success criteria that are to be met prior to DBVS radioactive operations.

\footnotetext{
${ }^{1}$ It must also be noted, however, that the assumption that all of the unaccounted for technetium is soluble is technically indefensible. The fact that it is being made, however, indicates the importance of achieving better closure on this issue.
} 
Area of Concern \# 8: The lack of a validated approach for control of the ICV ${ }^{\mathrm{TM}}$ process puts the project's ability to proceed to radioactive operations at risk The project has not yet been able to produce a filled ICV ${ }^{\mathrm{TM}}$ container without a major process upset (i.e., there has not yet been a successful demonstration of control of the $\mathrm{ICV}^{\mathrm{TM}}$ process). There is no firm basis for determining how to maintain a "cold cap" on the melt, nor how thick the cap should be. The project is still determining the optimum temperature range for operations. There is no monitor for salt formation, nor for "hot streaking" - diversion of the flow of electric current to a path more conductive than the molten glass. If the separate molten salt phase produces a continuous more electrically conductive path, then the melt will cool, while the salt will be superheated. Process control must be clearly understood and defined, and its effectiveness demonstrated, in order to move through the readiness reviews prior to initiating DBVS operations.

Potential Mitigation: The project should complete development of its Process Control Plan, and begin testing its effectiveness in enginecring- and full-scale tests as soon as possible. Demonstrating the effectiveness of the PCP should be considered a prerequisite for full-scale system commissioning.

Area of Concern \# 9: A feed qualification step is needed as part of the process control plan

The current plan for the DBVS includes significant compositional variation during radioactive operations, supported by limited non-radioactive testing. Although the vitrification system has been tcsted most extensively, even there little testing has been done with an accurate simulant of $S-109$, and none with the other compositions that will be used. Thus, the project should include a feed qualification step as part of its process control plan for radioactive operations to ensure that the significant changes in feed composition do not introduce unforescen process conditions, nor result in non-compliant products.

Potential Mitigation: The fecd qualification step should include such activities as determination that the feed composition is within the demonstrated bounds of the process, a flowsheet run to identify any potential process problems, thermogravimetric analysis to avoid problems associated with high temperature phase transformations, and other activitics needed to ensure safe and reliable production of a compliant product.

Area of Concern \# 10: The lack of prototypic testing prevents the project from predicting future compliance from past success

The ICV $\mathrm{IV}^{\mathrm{TM}}$ products produced to date have been remarkably uniform in both composition and performance, and have met product performance requirements. However, these containers have been made from well-mixed powders rather than the process that will be used by the DBVS. The dryer and the dried feed system appear to provide several opportunities for feed segregation. Depending on the required frequency for SMF backpulsing, this might also introduce significant non-uniformity into the melter feed. It has becn well-established that non-uniform feeds are more likely to be susceptible to formation of second phases (especially highly soluble salt phases) than more homogeneous feeds. 
The feed compositions used have also generally been non-prototypic. Only limited testing has been performed using a representative simulant of S-109. None has been performed using the other compositions that will be used during radioactive DBVS operations. As a result, it is not possible to project future DBVS success from the testing carricd out to date.

Potential Mitigation: The project should carry out prototypic testing at an engineering scale or grcater to demonstrate that product requirements can be met with the process that will be used by the DBVS. This could be accomplished as part of commissioning. However, performing this testing prior to commissioning would allow the project to avoid excessive delays if modifications to the DBVS were necessary. Suggested Improvements

\section{Suggested Improvement: The DBVS Project should perform additional testing to} further assess compositional variability.

The approach and resultant LAW compositions intended to bound the expected waste compositions for altemative treatment are reasonable as an initial demonstration.

Additional considerations for future testing need to consider the following process and composition parameters:

- Effect of oxidative leaching in the WTP pretreatment facility. This has been noted in the project's planning documentation.

- Effect of cases of low waste loading, e.g., $5 \mathrm{wt} \% \mathrm{Na}_{2} \mathrm{O}$ on processing conditions and glass product. The current flowsheet does not support the addition of additional alkali as a glass former in contrast to WTP. If processing these wastes will require high-viscosity, high-temperature melts, current Horn Rapids Test Site work as not assessed these impacts on production rate, production stability, and product quality.

- Compositional variation due to uncertainty in analytical and process measurements; could skew ratio of waste to glass formers $+5 \%$ or more.

- Effect of feed pile thickness on process, e.g., melt stability and rate, off-gas composition, retention of Tc, I, and organic Destruction Removal Efficiency (DRE).

- Effect of moisture content of feed on process; e.g., pressure fluctuations, gas rclease, melt stability and rate, off-gas composition, retention of $\mathrm{Tc}, \mathrm{I}$, and organic DRE.

- Effect of recycle on feed properties and process operations.

Suggested Improvement: The DBVS Project should consider developing an "engineered" refractory system to provide better leak-tightness for separate salt layers

This could consist of chemical additives (e.g., fly ash) to inhibit the mobility of soluble technetium, or of physical changes to the equipment (e.g., redesign of the refractory to ensure that all joints remain under compression). 
Suggested Improvement: The DBVS Project should consider redesigning the ICV ${ }^{\mathrm{TM}}$ lid to reduce lid warping potential Large-scalc test documentation has shown that the $\mathrm{ICV}^{\mathrm{TM}}$ lid is subject to warping. The lid design must be sufficiently robust so that it can withstand maximum expected temperatures without wapping, because warping could compromise the project's ability to handle the $\mathrm{ICV}^{\mathrm{TM}}$ container without spreading contamination. Test report results indicate AMEC may address potential warpage only with a change in the bleed air distribution system. Reliance on effective air distribution, flow rate and temperature may not be prudent; the project should reconsider the lid's design.

\subsection{Off-Gas Treatment System}

The purpose of the OGTS is to remove harmful contaminants in the bulk vitrification process gas strcam, prior to release into the atmosphere, and to capture all secondary liquid effluents produced by the OGTS. The design of the OGTS is intended to scrub, condense, filter, adsorb, chemically treat, and catalytically reduce both particulate and gascous contaminants and to oxidize $\mathrm{CO}$ to $\mathrm{CO}_{2}$. It is the last line of defense in protecting the cnvironment.

The OGTS comprises the following components which wcre evaluated: sintered metal fiber filters; wet scrubbcr; high efficiency particulate air filter; high-efficiency gas absorber; sclective catalytic reduction unit; OGTS emergency by-pass filter system; exhaust fans; stack monitoring system; and instruments and controls

The overall OGTS was evaluated, including system operation, flow balancing, and interaction of the system components and controls.

\section{Technical Issue \# 12 - Design criteria for the Off-Gas Treatment System have not} been clearly defined

In a number of areas the design critcria for components of the OGTS are not clcarly defined or differ between design documents and the equipment procurement specifications. Design criteria for equipment must be clearly established for both Normal and Upset conditions. The equipment specifications should clearly define the Design Conditions, Operating Conditions and all Upset or Emergency conditions to enable the equipment manufacturer to properly design and test the equipment.

Potential Mitigation: The ERP rccommends that the DBVS Project improve its design and specifications control as required by ASME NQA-1. Where there is uncertainty of design critcria, worst case scenarios should be used to establish the correct design criteria.

Technical Issue \# 13: Testing requirements in equipment specifications have been inadequately defined

Equipment spccifications do not include requirements for performance testing of the equipment at critical design conditions. In many cases, manufacturer's standard testing was accepted. Examples are the charcoal filers being procured with a residence time $50 \%$ 
less than specified. The organic removal efficiency of the charcoal was established based on activity, rather than retentivity, by the vendor. Both of these issues will be discussed under the HEGA Skid later in this report. Another example is the Sintered Metal/Metal Mesh Filter Specification that docs not include requirements for load testing although the specified design dust load is $7 \mathrm{lbs} / \mathrm{hr}$. This will also be discussed later under the SMF rcport. It should be noted that the SMF manufacturer will not provide a performance guarantee

Potential Mitigation: The ERP recommends that testing protocols be included in the equipment specifications to establish the performance envelope of the cquipment. Field testing protocols should also be established to define the performance envelope of the OGTS.

Technical Issue \# 14: Potentially large variations in system component pressure Iosses and the hystercsis within the control systcm could result in unacceptable response time to achieve proper flow

Overall system flow balancing may be difficult, if not impossible, to achieve due to the potential for large variations in component and system pressures and the hysteresis of the control system. The basic control premise for the OGTS is to maintain a constant volume with filtered make-up air. This is accomplished by adjusting dampers, valves, and/or fan speed. Potentially large variations in system component pressure losses and the hysteresis within the control system itself could result in unacceptable response time to achieve now adjustment. This potential must be carefully evaluated to avoid an upset condition. The high derivative term in the proportional-integral-derivative controller is needed for this systcm.

A complete instrument and control performance and interaction evaluation is needed to ensure that control of the system can be achicved and maintained.

Potential Mitigation: The ERP recommends that a complete instrument and control performance and interaction evaluation is carried out to ensure that control of the system can be achieved and maintained.

Technical Issue \# 15: The sintered metal filters will frequently blind, with a significant risk of release of contamination

The purpose of the SMF is to remove particulate from the off-gas from the ICV ${ }^{T M}$ box. The design basis is to return the particulates removed by the SMF to the dryer by vacuum transfer.

The ERP believes that the SMF design is deficient. The metal mesh filter is specificd at a high cfficiency, $99.97 \%$ efficiency when challenged with 0.3 micrometer particles. This is accomplished with two SMFs in series each rated at $99.95 \%$ to achicve the $99.97 \%$ efficiency. This type of filter is not designed for dust loading. The particulate the load in process gas stream to the SMF, as defined by the design specification, is $7 \mathrm{lbs} / \mathrm{hr}$ of particulate with a mean particle size distribution of 1 micrometer. The concern is that the SMF will blind very quickly which could potentially pressurize the $\mathrm{ICV}^{\mathrm{TM}}$ container and 
will definitely shut the off-gas system and cause the off-gas to divert to the Emergency By-Pass Filter System. A pressure spike above 0.5 psi will rupture the Emergency ByPass HEPA filter; a pressure spike above 1.0 psi will blow the filter out causing a release of contaminants to the atmosphere. Objective evidence was not provided to demonstrate that the OGTS Control System is capable of preventing this condition. In the event that the pressure spike does not vent through the Emergency By-Pass Filter System than a pressure spike will be sent back to the $\mathrm{ICV}^{\mathrm{TM}}$ container also causing a release of contaminants. This condition must be corrected for the DBVS to be viable.

Potential Mitigation: The ERP recommends that testing be performed to demonstrate that the SMF will not load more quickly than it can be cleaned. In addition, testing must be performed to ensure that there is only minimal deterioration in the performance of the SMF after repeated cleaning. The clcaning efficiency must be determined. The above information is also needed to design the vacuum transfer systcm.

Also notc that a Performance Guarantec is specifically excluded by the SMF manufacturer. The manufacturer states "the customer/user will need to validate the suitability of such cquipment in their own system against a range of actual process \& environmental operating conditions".

The ERP also recommends that the DBVS investigate the potential use of a "roughing" filter in front of the SMF to reduce the dust loading. This could be achicved by replacing the first SMF with one of a lower efficiency.

Area of Concern \# 11: Equipment manufacturers' standard practice appears to have taken precedence over code compliance for the Off-Gas Treatment System Equipment specifications do not require full compliance to ASME AG-1 Code on Nuclear Air \& Gas Treatment; ASME Standard N509 Nuclear Power Plant Air Cleaning Units and Components; or ASME Standard N510 Testing of Air Treatment Systems as required by DBVS System Specification No. RPP-17403, Rev 4, Para. 3.3.1.7. A fractionalized interpretation of code and standard requirements defeats the intent of the code. Although the project's System Specification and other design documents require compliance to the ASME Codes and Standards, equipment specifications require compliance to only a few sections of the codes and standards. A less than rigorous attitude toward code compliance seems to have been adopted allowing equipment manufacturer's standard practice to take precedence over code requirements. ASME Code AG-1 provides requirements for the performance, design, construction, acceptance testing, and quality assurance for equipment used as components in nuclear facilities. Its purpose is to assure that the equipment is acceptable in all aspects of performance, design, construction, and testing. If interpretation of the code is needed, ASME AG-1 Code has provisions to submit written requests for interpretations. This avoids multiple and/or incorrect interpretations of the code. DBVS has special requirement beyond commercial nuclear power plants. For that reason the code requires all design criteria to be specified by the owner or his designee. 
ASME Code cannot be fragmented. CH2M HILL's approach to code compliance is to go through the code and trying to determine compliance and/or applicability on a line-byline basis. There are two weaknesses with this approach; the first is that overall code requirements are missed (not seeing the forest for the trees). Secondly, the lack of compliance is accepted without sound engineering justification.

Design, construction, manufacturing, testing, and quality assurance requirements of the Code will not be met without compliance to ASME Codes and Standards. In addition, the equipment may not function as required. Compliance to ASME Codes and Standards is necessary to provide the high degree of reliability necessary for Government and Public acceptance.

Potential Mitigation: The ERP recommends that the DBVS Project specify full compliance to ASME AG-1 Code to ensure equipment design, manufacturing, quality and testing requirements are met. The equipment specification must clearly define that the complete code and standards apply, including the general requirements, materials, design, manufacturing, quality assurance and design control, as they relate to the specified equipment.

Also note that a Performance Guarantee is specifically excluded by the SMF manufacturer. The manufacturer states "the customer/user will need to validate the suitability of such cquipment in their own system against a range of actual process \& environmental operating conditions".

The ERP also recommends that the DBVS investigate the potential use of a "roughing" filter in front of the SMF to reduce the dust loading. This could be achieved by replacing the first SMF with one of a lower efficiency.

Area of Concern \# 12: The Wet Scrubber specification does not require performance testing to demonstrate the specified removal efficiencies The purpose of the Wet Scrubber is to remove acid gases, e.g., nitric oxide, from the offgas stream coming from the SMF. The off-gas is quenched with a caustic solution to cool it before entering the venture scrubber. After the scrubber, entrained water is removed from the off-gas by a mist eliminator. An electric duct heater is used to reduce relative humidity. Acid gases and entrained moisture must be eliminated so as not to adversely affect the HEPA Filter or HEGA Adsorber Units.

The specification does not require performance testing to demonstrate the specified removal efficiencies of ninety-seven percent $(97 \%)$ removal of $\mathrm{HCl}, \mathrm{HF}$, and $\mathrm{SO} 2$ and $40 \%$ removal of NO2. The design and sizing calculations provided demonstrate that the Wet scrubber components are sized correctly. Duratek Procurement Specification PSWSS-001, Article 6, indicates Test and Inspection requirements are N/A. Duratek did submit a Wet Scrubber Skid Performance Acceptance Test Plan, Document No. TPWSS-001, Rev. 1. This document, although titled "performance" is an operational \& functional test only. Performance is not verified. 
Potential Mitigation: The ERP rccommends that testing protocols be included in the equipment specifications. Qualification testing will determine the suitability of the equipment for the application and establish the performance envelope of the equipment at design, operating and upset conditions.

Area of Concern \# 13: Design criteria for the HEPA filters (e.g., concentration of acid gases) have not been established

The purpose of the HEPA Filter Skid is to remove particulates from the off-gas stream with an efficiency of $99.97 \%$ on 0.3 micrometer particles. Nominal particle size of 0.3 micrometer particles has been determined to be the most penetrating particle size for systems designed to ASME AG-1 Code. Two filter trains are provided, one normally opcrating and one on standby. A pneumatically operated isolation valve is provided at the inlet of each unit. Isolation valves to facilitate filter change-out are located downstream of the HEGA Skid. Each filter train includes test section and two HEPA filters in series. Consideration should be given to utilizing a 90\% Amcrican Society of Heating, Refrigerating and Air Conditioning Engineers Filter in front of HEPA filters if established performance criteria indicate a particulate challenge with a mean diameter above 0.5 micrometer.

Design criteria for the HEPA Filters, such as the concentration of acid gases, HF, HCL that affect the filter media, binders, adhesives/potting compounds and gaskets, have not been established. The project's response to questions indicated that standard government furnished cquipment (GFE) would be used. This specific application has design, and environmental conditions not necessarily covered by standard GFE HEPA filters.

Potential Mitigation: The ERP recommends that the DBVS Project establish design criteria, rewrite or strengthen procurement specifications, and require appropriate performance testing by the vendors.

Area of Concern \# 14: Carbon cells for HEG $\Lambda$ filters do not meet the required residence time as specified in the Procurement Specification and ASME AG-1 Code The purpose of the HEGA Adsorber Skid is to adsorb/remove organic compounds and any residual radioactive iodine. The HEGA Skid has two redundant trains, one normally operating and one standby. Each filter train includes test section, a charcoal adsorber and a polishing filter to prevent any carbon particles from carrying downstream into the Selective Catalytic Reduction Skid.

Removal efficiency - Carbon cells supplied by Flanders Corp do not meet the required residence time as specified in the Procurement Specification and ASME AG-1 Code. In addition, adsorption capacity data from vendor is inaccurate and/or misleading.

Activity values are provided by the vendor as capacity of the carbon. This is the maximum amount of contaminant that is adsorbed on the carbon at specific conditions when it is at equilibrium conditions with the sorbate. In a dynamic system, the gas 
challenge concentration to the bed is equal to the outlet bed concentration. Values are typically reported as grams of contaminent/100 grams of charcoal.

The removal efficiency of charcoal for a specific contaminant (Retentivity) is much less than the activity and is an important parameter because it represents the design saturation limit of the adsorbent for the application.

The basis of the calculations is capacity data provided by the vendor. The capacity provided is Activity rather than Retentivity. The actual breakthrough time could be within a few hours. Actual adsorption isotherms should be developed for the specific contaminants at the actual operating conditions, including all criteria noted above that affect adsorption. The type of impregnated carbon is a key consideration. Adsorption isotherms for the expected components must be provided.

Potential Mitigation: The ERP recommends that the DBVS Project: 1) establish design criteria; 2) perform laboratory-scale testing to validate charcoal adsorbcr (testing should include the possibility of sclective desorption and potential chemical interaction of contaminants); 3) rewrite or strengthen procurement specifications; and 4) require appropriate performance testing by the equipment manufacturers.

\section{Area of Concern \# 15: There cxists a potential for a charcoal fire due to concentrations of $\mathrm{NO}_{x}$ in the HEGA skid}

This issue has not been adequately addressed even though a fire occurred in a similar installation at Hanford. (See DBVS-LDS-016 Letters dated April 21, 2005, \& March 24, 2006 James R. Divine, PhD, ChemMet, Ltd. Chief Engineer). Concerns regarding desorption and potential hot spots within the carbon bed are also detailed in Letter Report VSL-05L5290-2, Off-Line DM1200 Slipstream Carbon Column Scoping Testing by Marek Brandys et el, Vitreous State Laboratory, The Catholic University of America, Washington, D. C.

Potential Mitigation: In addition to the same recommendations listed above for Area of Concem \#17, the ERP recommends that the DBVS Project consider multiple carbon beds with impregnated charcoal formulated specifically for the gaseous contaminant to be removed. This could result in a step process to remove acid gases, organic compounds, etc.

Area of Concern \# 16: The Off-Gas Treatment System emergency by-pass filter system could quickly load with particulate during upset conditions, rcsulting in a filter failure and release of contaminants to the atmospheres The purpose of the Off-Gas Emergency Filter System is to provide a path to vent the hot gases from the $\mathrm{ICV}^{\mathrm{TM}}$ melt during upset conditions. During upset conditions, the OGTS will be isolated and the hot gas will pass through the OGTS By-Pass System HEPA Filter and vented directly to the stack. The HEPA filter is specified as a standard extended glass media filter. 
During upset conditions, such as blocked SMF's, the OGS will divert and go through the emergency by-pass system. The particulate load from the $\mathrm{ICV}^{\mathrm{TM}}, 7 \mathrm{lbs} / \mathrm{hr}$, will quickly load the HEPA filter which could cause a filter failure and relcase of contaminants to the atmosphere. Another concern is that that the filters in the emergency by pass system do not appear to have been designed for the corrosive materials that will be in the off-gas, giving further cause for concern regarding potential filter failure and relcase to the environment.

Potential Mitigation: The ERP recommends that the DBVS Project redesign the OGTS Emergency By-Pass System to handle Abnormal or Upset design conditions.

\subsection{Overall System Design}

Area of Concern \# 17: There appears to be little, if any, design optimization During the revicw the team found a number of design process issucs which causcd major concems regarding both the functionality of the cquipment and the liability of the vendors supplying the equipment. They are:

- The use of "hand me down" cquipment bought for other projects is seen as an area of concern.

- Other than work on the melter there appears to have been little, if any, design optimization.

- To date there has becn no opcrational research modeling which it is felt should be a key tool to support plant design and opcrational optimization.

Potential Mitigation: The ERP rccommends that the DBVS Project conduct a design optimization study primarily aimed at simplifying the overall design and improving the robustness of the plant functionality and that an operational research model of the DBVS system be constructed and used to support the plant and operability studies. 


\section{Secondary Waste Treatment System}

The DBVS produces waste streams that are sent cither to plant-wide treatment and disposal facilities not within the DBVS Project, are recycled back into the DBVS, or go up a stack. Most liquid waste effluents will be sent to the Effluent Treatment Facility (ETF). Solid wastes such as the spent HEPA and HEGA filters are to be sent to Hanford's IDF. An exhaust stack will be provided for release to the environment of gaseous wastes.

The waste streams are called secondary wastes and their management is called Secondary Waste Treatment. Requirements on secondary wastes are that their volumes and masses not be so large that their disposal is burdensome cither financially or in their handling. Furthermore, the radioactivity of the secondary wastes must meet formal regulatory disposal permitting specifications and treatment facility acceptance criteria. Because no bulk waste vitrification tests have been made that include the proposed flowsheet processes that generate secondary wastes, the flowshect information on their amounts and their natures is based on reasoned assumptions. If these assumptions are substantially in crror, or if in some cases the tank waste fced compositions are significantly different from those assumed, the sccondary waste volume, mass and radioactivity estimates may be seriously in error. In such cases acceptable regulatory and/or waste acceptance limits on the wastes may be exceeded, lcading to problems in their management. These are the issues addressed in the following section.

Area of Concern \# 18: The scrubber system may not be able to treat unexpectedly large amounts of gases and solids, resulting in unacceptable amounts of material being directed to the ETF

The off-gas scrubber system may not be able to treat unexpectedly large amounts of gases and solids, resulting in unacceptable amounts of matcrial bcing directed to the ETF. There is a wet scrubber system in the OGTS that treats nearly 19 million cubic feet of off-gas for each $\mathrm{ICV}^{\mathrm{TM}}$ box filled. It is anticipated that the scrubber will be charged with 2570 pounds of carbon dioxide for each $\mathrm{ICV}^{\mathrm{TM}}$ box filled. When this carbon dioxide reacts with the sodium hydroxide in the scrubber approximately twice that mass of sodium carbonate will be formed. To kecp the scrubber solution from becoming saturated it is necessary to remove a "bleed stream" and to replace the volume removed with fresh sodium hydroxide solution. This bleed stream goes to the ETF, which is not part of the DBVS and handles wastes from many parts of the Hanford site. In addition to the carbon dioxide, it is anticipated that there will be nearly 4 pounds of sodium phosphate and scveral pounds total of a wide varicty of other solids. If a larger amount of gas and solids than planned for enters the wet scrubber system because of excessive air flow in the DBVS, or if larger amounts of solids are carried through the system, perhaps because of unexpected carryover from the dryer, then the scrubber system will be challenged and unacceptable amounts of material will be directed to the ETF. 
Potential Mitigation: The ERP recommends that the DBVS Project reduce where possible the very large volume of air introduced throughout the DBVS, e.g., the off-gas makeup air, and/or reduce the amount of caustic used in the OGTS (this is related to reducing the amount of air used and to the amount of nitrogen dioxide produced in the melter).

Area of Concern \# 19: Assumptions about types and amounts of chemicals entering the Solid Waste Treatment System

The flowsheet is largely based on many assumptions about types and amounts of chemical species through the DBVS. Many of these assumptions lead to additional assumptions about what solid and toxic materials enter the Solid Waste Treatment System (SWTS). For example, toxic nitrogen oxides and carbon monoxide gases are present and solids from the wet scrubber are introduced In addition, the toxic chemicals ammonia and sodium hydroxide are introduced directly into the SWTS. More and better data are needed about the amounts and ultimate fates of these materials.

Potential Mitigation: The ERP recommends that the DBVS Project examine and validate the assumptions about the materials that are especially toxic and in significant amounts and those materials that form solids during off-gas ncutralization in the wet scrubber. 


\section{Operations and Maintenance}

The Operations and Maintenance review focused on three objective areas to meet the review team's overall objectives and focus areas provided in the DBVS ERP chartcr. These objective areas were:

- Verify the DBVS facility, system and component design and incorporated ease and simplicity of operations, ease and accessibility of maintenance and repair, minimization of the generation of secondary waste, facilitated future decontamination, decommissioning and disposal and facilitated testing, inspection and in service surveillance of safety class systems.

- Evaluate the feasibility of DBVS operating concepts and maintenance stratcgy.

- Evaluatc DBVS testing, startup and readiness strategies and plans and assess the ability of the DBVS to receive operational approval by DOE.

\section{6,1. Background}

The primary purpose of the DBVS demonstration is data collection to qualify the bulk vitrification waste form and support a decision on implementation of a future production scale system. Due to the specialized nature of the equipment and systems, and the $\mathrm{RD} \& \mathrm{D}$ aspects of the project, responsibility for operating and maintaining the DBVS facility has been assigned to a subcontractor, AMEC Earth and Environmental, Inc.

The demonstration will be conducted over a short period of time, approximately 18 months to 2 ycars, and produce up to $50 \mathrm{ICV}$ TM boxes for temporary storage in the facility and ultimate disposal in the Hanford site IDF. The demonstration is limited to 400 operating days, nor more than 2 calcndar years, and 50 ICVTM boxes followed by decontamination, decontamination and decommissioning (D\&D). Individual campaign plans are required to be developed by the project and approved by the Washington State Department of Ecology for each ICVTM or series of ICVs ${ }^{\mathrm{TM}}$.

An integrated operating and maintenance cycle for the life of the project has not yet been developed. Operation consists of an eight day operating cycle to produce one box. The operating cycle, from waste receipt, feed preparation and delivery to melt, subsequent cool down and temporary storage of one ICVTM box is based on continuous 24 hour per day operations with an operational and support staff of 50 people organized into 5 shifts. This staff estimate does not include CH2M HILL personnel required to provide oversight functions, or supporting staff personnel such as engineering, testing, maintenance, management, or training support personnel. The project assumes a Total Operating Efficiency of $70 \%$ to account for unplanned maintenance and operational outages. 
The current commissioning approach requires successful completion of a DOE Operational Readiness Review after conducting integrated system cold testing using the first 2 of $50 \mathrm{ICV} \mathrm{TM}^{\mathrm{M}}$ boxes and only clean soil and simulants as feed.

\subsection{Findings}

No mission critical or technical issues were identified that would result in the failure of the DBVS demonstration system to mect established DBVS system performance requirements. Specific equipment operability, reliability and maintainability issues that the team believes could result in or contribute to a mission critical or technical issue have been addressed in the corresponding equipment design section of the report. Three areas of concern were identified that could result in the necd for changes in the technical basis or equipment/system design, or may require additional testing to determine if the design is adequate (now or later).

\section{Area of Concern \# 20: The potential for future use of the DBVS facility as a single} line production facility and gap filter capability might not be adequately addressed in the existing design

The existing design basis, operating and maintenance approach and performance criterion are based on a demonstration of short duration ( $\sim 2$ years) followed by D\&D. Although there is recognized potential benefits for the future production use of the DBVS facility should the demonstration prove successful, the current design and maintenance strategy will not support future use without a potentially lengthy shutdown and costly service life extension program to identify and accomplish necessary process system modifications or cquipment replacement requirements. Detailed engineering revicw and matcrial condition assessments would be required to evaluate maintenance, repair, modification or replacement actions necessary to extend the service life of the facility's process systems and components to support safe operation beyond the current 2 year service life and the current 5 year design life.

Current design of some DBVS components and systems such as the waste receipt system storage tanks, dryer or dried waste handling system is not optimal for future production or.longer term use. The practical implications of the effects of implementing a minimal maintenance philosophy combined with decisions not to establish a Reliability, Availability, and Maintenance (RAM) program or require a reliability-centered maintenance (RCM) analysis on component operability, reliability and availability increases the risk that demonstration reliability and maintainability objectives may not be met. As a result, there is little confidence the current strategy will support reliable equipment operation beyond the current service life and may not provide the material history, operability and maintainability data necessary to support engineering reviews or matcrial condition assessments in a cost effective manner.

Under the current permit, the DBVS facility would undergo D\&D following completion of the demonstration project, rather than continue operation as a limited single line 
production facility to vitrify LAW and contribute to risk reduction, even if the demonstration proved successful. This approach using short service and design lives for the facility and its components, systems, and major equipment appears to be contradictory to the common standard within DOE and Department of Defense (DOD) activities conducting nuclear operations that facilities designed to conduct such operations should minimize both the cost of clean up and the generation of waste requiring eventual disposal.

In view of these uncertainties and unknowns regarding the DBVS design and future expectations, a future decision to continue use of the facility beyond the initial demonstration period, if successful and desirable, may not be possible on the basis of cost alone. While the costs of project actions now to address design issues and develop a complimentary reliability based maintenance approach together with establishing data quality objectives for the collection of maintenance data and material history records are real, failure to consider these changes now will limit available options in the future.

Potential Mitigation: The ERP recommends that the DBVS Project consider the following actions:

- Reevaluate the cost effectiveness of establishing increased service and design life performance requircments to support future operational use of the facility without the need for service life extension or unnecessary equipment maintenance, repair, modernization or replacement.

- Establish a graded RAM program, require the subcontractor to conduct a graded to RCM analysis and define appropriate data quality objective requirements to collect necessary operability and maintainability data to support either a service life extension program or improved life cycle performance data for a production facility.

- Evaluate contractual methods that will better ensure that DBVS complies with DOE maintenance management requirements and develop a better defined, coherent maintenance strategy that supports the immediate demonstration objectives while preserving the option to continue future production use in a more cost effective manner.

Area of Concern \# 21: An adequate maintenance strategy has not been developed and incorporated into the demonstration facility requirements Operations and maintenance responsibilities have been assigned to a sub-contractor with relatively little experience in operating or maintaining nuclear facilities. Maintenance strategies and plans have not been fully developed and project documentation contains contradictory or inconsistent maintenance performance requirements and goals. Furthermore, because DBVS is constrained by the existing permit to be a short duration demonstration, the project has judged that the subcontractor is neither required to establish an overall reliability, availability and maintainability program, nor perform a reliability centered maintenance analysis.

The DOE order governing DOE nuclear facility design and construction requires hazard category 1,2 , and 3 nuclear facilities be designed to facilitate inspections, testing, 
maintenance, repair and replacement of safety structures, systems, and components as part of a RAM program. Neither the Project Execution Plan nor the subcontract Statement of Work requires the DBVS subcontractor to perform a RAM or RCM analysis because DBVS equipment has less than a 2-year life and the short-term operating duration of the demonstration. The project's decision to eliminate the requirement for a RAM analysis rather than conduct a graded or limited RAM program and RCM analysis introduces greater uncertainty and risk into the project that the demonstration may not meet its demonstration goals in a safe, reliable and compliant manner.

The overall maintenance strategy and concepts to support safe operation are not well defincd or documented in Project documents. As a result, it is difficult to assess or report on the feasibility of the Maintenance Strategy. The minimal maintenance approach prescribed and the heavy reliance on vendor recommendations for maintenance is likely to result in component and overall system performance reliability and operability not mecting expectations, an increased number of operational upsets and subsequent delays in recovery from off normal conditions, an increase in equipment failures and corresponding reductions in system opcrational availability. The modular approach used in fabricating and delivering the major systems and some procurement practices may result in non-standard components selection for like functions increasing sparing requirements and training and maintenance requirements.

CH2M HILL has significant nuclear facility operating and maintenance management experience and established DOE compliant programs, including a mature Integrated Safety Management System. As discussed in the safety section of the report, it is not clear how and by what mechanisms the subcontractor, responsible for preparing its own safety management programs for operating and maintaining the DBVS and training and qualifying not only subcontractor personnel, but CH2M HILL personnel conducting DBVS related functions, will benefit from CH2M HILL's experience and expertise in nuclear facility opcrations, training and maintenance.

Potential Mitigation: The ERP recommends that the DBVS Project consider the following actions:

- Develop or require the subcontractor to develop and evaluate an integrated operating and maintenance cycle plan to best support demonstration objectives. Conduct a task analysis using this plan to evaluate the adequacy of current staff estimates for project cost and schedule implications.

- Revicw existing Project Documentation, strengthen flow down of requirements and eliminate contradictions and inconsistencies in Operations, Maintenance and Training sections especially between the project Execution Plan and the Statement of Work of the Subcontract.

- Evaluate existing contract requirements for vendors to conduct component performance testing under normal operating and design conditions and strengthen contract mechanisms to ensure adequate performance testing of procured cquipment has been performed.

- Reevaluate the need for and perform additional testing to support design and performance requircments and to better understand and plan for the maintenance 
that may be required to support reliable opcrations especially as it pertains to the dryer and dried waste handling systems.

Area of Concern \# 22: Readiness requirements for ultimate hot operations may be underestimated

The project does not have a well-defined or fully developed commissioning and startup strategy. In addition, readiness requirements for hot operations may be underestimated. The project Execution Plan requires a combined readiness effort led by CH2M HILL's Operational Readiness organization. The subcontract Statement of Work assigning the subcontractor responsibility for operating and maintaining the DBVS facility requires them to support $\mathrm{CH} 2 \mathrm{M}$ HILL in the conduct of formal readiness preparation and review activities using the existing $\mathrm{CH} 2 \mathrm{M}$ HILL readiness program. However, $\mathrm{CH} 2 \mathrm{M}$ HILL's existing Operational Readiness organization does not have recent (within the past sevcral years) practical experience in managing, coordinating or leading a comprehensive readiness program to achieve the requisite readiness for a project of this size and scope.

Already noted is the subcontractor's relative inexperience operating or maintaining DOE nuclear facilities, and they will have to recruit, hire, train and qualify most of the required operating or maintenance staff between now and the projected start of operations. Use of a subcontractor to operate and maintain the facility together with the integration of the subcontractor and $\mathrm{CH} 2 \mathrm{M}$ HILL safety management programs represents a key project risk in achieving readiness and project delivery. Formal and periodic strategies and plans to achicve the necessary oversight and assure contract compliance beyond delivery of initial deliverables have not been developed.

The current plan to achieve readiness for hot operations (introduction of radioactive or mixcd waste into DBVS) relies on just 2 ICVTM boxes to perform integrated cold testing of the facility and final grooming and balancing of key systems such as the off-gas treatment system. Because there are limited opportunities to establish and assess operational proficiency, and conduct of operations and operating practices until the integrated test program, developing sufficient operator proficiency and assessing operational readiness of cquipment, systems and personnel prior to conducting hot operations will be an equally important objective during the integrated cold test program. The revicw team does not belicve that these readiness objectives can be fully achieved with only 2 boxes.

Expericnce both within DOE and DOD activities performing radiological work in complex environments has shown that training and qualifying radiological workers alone does not result in the requisite proficiency needed to conduct consistently safe, efficient and compliant radiological work. This can only be established through the frequent conduct of actual work with proper supervision and through the use of mock-ups. 
Potential Mitigation: The ERP recommends that the DBVS Project perform the following actions:

- Accelerate Operational Readiness Checklist development and integrated readiness planning. Add a dedicated and graded operational proficiency period into the schedule to support achievement of readiness objectives.

- Build a realistic, scaled Ancillary Waste Transfer Enclosure (AWTE) mock up facility based on the final design or retaining and modifying, as necessary, the most recent AWTE mock-up built and used to facilitate the current AWTE design from ergonomic and accessibility standpoints for future use in initial training and qualification programs and to support developing worker radiological work proficiency.

- Evaluate the need for conducting additional integrated cold testing and the impact on the demonstrations overall objectives and the ability of the integrated test plan to meet those objectives, if more than 2 boxes are needed to complete the test program.

- Ensure that clcar roles and responsibilities are documented and published soon to implement a combined readiness program to start at the earliest opportunity and address how key programs, such as the Cognizant System Engineer Program will be implemented and exccuted. 


\section{Safety}

The Nuclear Safety Sub-Team of the DBVS Expert Review Panel (ERP) focused its review on the ability of the DBVS Project to meet nuclear safety and operational standards required for a pilot scale nuclear facility. The safety review included specific evaluation of the project's implementation of Nuclear Safety, Authorization Basis, and Integrated Safety Management requirements. The Safety Team tailored its approach by considering the stage of the project and the experience base of the CH2M HILL Tank Farms Project with order-compliant Authorization Basis documentation and implementation of Integrated Safety Management.

The DBVS Project has completed a significant amount of safety-related analysis as evidenced by an approved Preliminary Documented Safety Analysis (PDSA) developed carly on in the project and a well-structured and systematic identification of hazards in the PrHOA. In addition, a preliminary fire hazards analysis has been performed, a criticality safety evaluation completed and an ALARA design review of potential radiation exposures and contamination hazards has been recently updated. However, some of those safety analyses have been overtaken by other events, because safetyaffecting changes have taken place since the design information on which the approved PDSA was based. For this reason, documentation associated with the PDSA update was being prepared in parallel with this ERP review.

Opcrational safety in Tank Farm Operations is based on years of experience, and the implementing documents are clear, concise and apparently effective. Furthermore, the Integrated Safety Management (ISM) guiding principles and corc functions are followed at the Tank Farms and provide a logical framework for CH2M HILL's Safe Work Environment Initiative. While ISM has not been implemented at the activity level, the DBVS Project Exccution Plan implies that the DBVS Project will implement the Tank Farms ISM program. However, significant effort will be needed for the DBVS subcontractor to implement a compliant and effective ISM program at the DBVS Project.

\subsection{Findings}

Evaluation of requirements for Nuclear Safely, Authorization Basis, and Integrated Safety Management has led the Safety Team to develop the overall issues summarized below. The detailed bases for the development of each issue are documented in the Safety Section included in Volume 2 of this report. Volume 2 provides the complcte requirements-based review performed by the ERP on the status of DBVS safety. The summary issue definitions presented below were adapted from those used by the rest of the review team and are each expressed in terms of the following categories:

- Technical Issues - Issues that could potentially result in injuries, offsite contaminations, long shutdowns, major delays in start-up approval, and/or failed rcadincss assessments, if not addressed. 
- Arcas of Concern - Issues that could result in near misses, onsite contaminations, decline in plant availability, Potential Inadequacies in the Safety Analyses, positive Unreviewed Safety Questions (USQs), inquiries and questions by regulators, and declines in safety performance indicators, if not addressed.

- Suggested Improvements - Issues stemming from inadequate safety documentation that could result in potential delays in approval to proceed and/or failure to meet safety performance objectives, if not corrected.

Technical Issue \# 16: Testing and safety analysis have not adequately addressed the $\mathrm{ICV}^{\mathrm{TM}}$ melt box performance for containment of the melt product, volatile radionuclides, and generated $\mathrm{NO}_{\mathbf{x}}$

Project testing and safety analysis to date have not yet adequately addressed the $\mathrm{ICV}^{\mathrm{TM}}$ melt box performance for containment of the melt product, volatile radionuclides, and generated NOx. The ICV ${ }^{\mathrm{TM}}$ box is not doubly contained, and depends on vacuum maintained by the Off-Gas Treatment System to contain gaseous releases. The testing cxperience at Pacific Northwest National Laboratory and Horn Rapids has been extremely valuable, and lessons leamed are being applied. However, the number of unknowns and the near failures make it difficult to conservatively bound potential accident scenarios. As a result, the project has a risk of toxic gas or radioactive uptakes to operators and nearby workers, contamination of the work site and extended shutdowns of the pilot project.

Potential Mitigation: The ERP recommends that the DBVS Project consider several altemative actions that would help resolve this issue:

- A risk-rcduction/cost-optimization study of double-containment (e.g., small containment building with a safety significant ventilation system) versus single containment for the ICV ${ }^{\mathrm{TM}}$ box.

- A focused effort to reliably detect hot spots in the melt box and development of the associated recovery plan.

- Development of criteria and requirements for melt termination and restart.

- Install detectors to monitor NOx generation rates and pressurization in the $\mathrm{ICV}^{\mathrm{TM}}$ box.

Technical Issue \# 17: The safety performance of the Dried Vaste Transfer System to contain the dried waste under normal and accident conditions is not yet fully understood and defensible

The safety performance of the DWTS to contain the dried waste under normal and accident conditions is not yct fully understood and defended. The dry waste fecd system contains radioactive Material at Risk in dispersible forms, and vilnerable areas without redundant physical barriers may still exist. As a result, there is a potential for contaminations and radioactive uptakes by operators and nearby workers. A design that does not fully employ redundant physical barriers, if not adequately defended, may receive resistance by oversight and approval authoritics, resulting in approval delays or extensive back-fits. 
Potential Mitigation: The ERP recommends that the DBVS Project consider the following actions:

- Preparation of a DWTS confinement performance justification and development of a communications strategy with regulators and oversight organizations to effectively defend the chosen design approach.

- Performance tests to demonstrate the adequacy of DWTS design approach, particularly if any containment components could be viewed as unconventional.

- Installation and maintenance of a Safety Significant active, confinement ventilation system or leakage alarm system for portions of the DWTS with single physical boundary containment. (or in conjunction with a melt box containment building).

Techuical Issue \# 18: The DBVS Project plans to assign operational responsibility to a sub-contractor who has little formal nuclear facility operating experience The projedt presently plans to assign operational responsibility to a sub-contractor who has intimate knowledge of the design, but relatively little formal nuclear facility operating experience. The DBVS subcontractor runs a largely expert-based safety program that is based on extensive experience with similar glass melting operations and compliant with Occupational Safety and Health Administration industrial safety standards. However, the subcontractor does not have significant expcrience in the formality of operations required to operate a nuclear facility; nor does an ISM program, a formality of operations manual, or a mature training program. Success of the DBVS will depend as much on safe operations, as meeting waste specifications and operational efficiency goals. Lack of experience in the formality of nuclear operations can lead to unanticipated safcty non-compliances, a high rate of occurrences, and potentially, accidents.

Potential Mitigation: The ERP recommends that the DBVS Project flow down a required set of tank farm safety and operational standards to the DBVS subcontractor. Before being relcased to operate DBVS, the subcontractor should formally cvaluate CH2M HILL initiatives in ISMS, Voluntary Protection Program, Human Performance, Enhanced Work Planning/Worker Involvement, and Safe Work Practices for implementation. The manner in which $\mathrm{CH} 2 \mathrm{M}$ HILL will execute its oversight and safety assurance responsibilities should be clearly described in an interface working document. In addition, CH2M HILL and AMEC should collaborate to develop a commissioning/startup strategy and a deliberate operations plan that will develop experience prior to introducing radioactive waste to DBVS.

Technical Issue \# 19: Project uncertainty with various portions of the unit operations and process chemistry may heighten safety vulnerability under abnormal conditions Project uncertainty with various portions of the unit operations and process chemistry may heighten safety vulnerability under abnormal conditions. This may pose extra challenges to event recognition, condition recovery, and emergency preparedness and response. For example, the glass melting process could represent a significant hazard; high stored heat energy, toxic NOx, and the potential release of technctium and cesium 
suggest the possibility of a complex, high-hazard accident. Furthermore, operating experience with solids handling and the off-gas systems for DBVS is insignificant, the dry waste transfer system contains nuclear Material at Risk in dispersible forms and cesium will likely plate out in the off-gas treatment system.

Potential Mitigation: The ERP recommends that the DBVS Project consider a comprehensive identification of the process and chemistry uncertainties that could lead to off-normal conditions that would warrant unique approaches to emergency preparedness. The project should also consider rigorous process and scenario training for operators, including how to react to abnormal conditions, how to divert potential upsets and how to handle emergencies. The project should develop a deliberate operations preparation plan to accomplish this training and experience prior to introducing radioactive waste to the DBVS.

Area of Concern \# 23: Insufficient consideration to accumulation of radioactive materials throughout the DBVS could lead to avoidable radiation exposure during operations and extra complexity of the decontamination and decommissioning effort The project design to date has not given sufficient consideration to accumulation of radioactive materials throughout the DBVS. Consequences could involve avoidable radiation exposure during opcrations and extra complexity of the decontamination and decommissioning effort.

Potential Mitigation: The ERP recommends that the DBVS Project develop a conceptual D\&D plan and examine potential risks such as accumulations, deposits and plate-outs specific to the DBVS. Matcrials accumulation assumptions should be incorporated into the hazards and safety analyses material-at-risk, and also into rccommendations from the ALARA Analysis Report.

Area of Concern \# 24: The large number of Technical Safety Requirement - level safety systems and DBVS - specific administrative controls may be excessive from the standpoint of human factors and operational complexity The ERP expresses concerns regarding the potential impact of the DBVS Safety Systems and Administrative Controls on the operability of the plant. The number of individually designated TSR-levcl safety systems, as well as the number of DBVS-spccific administrative controls may be excessive from the standpoint of human factors and operational complexity. A disproportionately large number of TSR-level controls introduces the potential for causing technical violation of TSRs, complication of testing opcrations, lack of clear understanding by operators of the relative importance of the individual hazards and associated controls. The growth in administrative controls appears to be accompanied by a growth in the number of alarms that could lead to a certain amount of operator complacency with alarms. 
Potential Mitigation: The ERP recommends consideration of the following actions:

- Performance of a control optimization exercise to examine the origin of each TSR-level control; identify the associated analysis/evaluation conservatisms; determine the sensitivity to the conservatisms; and evaluate the necessity of each control.

- Examination of any design attributes that are driving the need for a safety control, and assess whether there are reasonable altematives that would result in simpler or fewer controls.

- Evaluation of the frequency and magnitude of surveillances, readings, recordings and adjustments in the safety administrative control programs for viability and human factors issues.

- Perform an update of the project Human Factors analysis, consistent with the latest identificd control suite.

Area of Concern \# 25: The documented rationale for the revised Hazard Categorization is insufficient

The documented rationale for the revised Hazard Categorization (HC-3) is not currently sufficient; issues revolve around the amount of radioactive material assumed to be in the system, the rationale underpinning a 'worst case' feed composition, and the potential for accumulation of releasable materials throughout the system. For example, the current hazard categorization documentation does not sufficiently defend the assumption that three full waste receipt tanks bound the maximum amount of material that can reside in the facility at one time.

Potential Mitigation: The ERP recommends that the DBVS Project consider a revision to the DBVS Hazard Categorization report to better describe the basis for the HC detcrmination. Additional effort should be expended to formulate a robust and defensible Material at Risk (MAR) assumption that accounts for (a) assumed characteristics of outof-spec waste, (b) the maximum wastc that can be resident in the facility at any point in time without credit for engineered and administrative controls, and (c) address potential accumulation of MAR in the DBVS components.

Area of Concern \#26: Safety documentation and analysis does not provide for a complete accounting of chemicals used and generated by the DBVS

The ETP is concerned that present project documentation implics an incomplete consideration of chemical hazards. Some chemical species used and generated in the DBVS are not quantified or explicitly addressed as part of the accident analysis materialat-risk, or as part of worker safety considerations. This observation is consistent with other ERP areas of concern regarding types and amounts of chemical species throughout the DBVS. Additionally, the documented rationale for determining the inapplicability of the Process Safety Management (PSM) Rule (29 CFR 1910.119) does not appear to be consistent with applicable DOE guidance.

Potential Mitigation: The project should develop a comprehensive list of bulk cold and generated chemicals, systematically estimate the associated quantitics of each, and specify their locations and forms. The results should be used to validate or update the 
PrHOA and the PDSA accident analyses. Additionally, the project should use the results to compare the quantities of all the chemical species to the TQ values used to evaluate applicability of the PSM Rule. The project should consider a review of the 14 elements of the PSM Rule and evaluate how application to the DBVS could assist in ensuring safety.

Suggested Improvement: The DBVS Project should consider more explicitly stating its project-specific Safety Objectives in its Project documentation Project documentation does not explicitly reflect any clear safety-related objectives for the DBVS. The lack of stated goals and objectives could give the impression that safety is not a major Project priority. Further, without some level of performance measures for the demonstration, there may not be a well-understood basis for risk reduction and safety improvement for the full production facility. There may also be a risk of not meeting assumptions made in the design estimates for worker exposure.

In order to help resolve these issues, the project should consider the issuance of a statement of overall radiological, chemical and industrial safety objectives. The objectives should consider the development of goals and performance measures for radiation exposure, chemical release/exposure, and safety incidents. Goal development should take into account the specific nature of the DBVS process and its hazards compared to other established Tank Farms and DOE complex operations as benchmarks. Consideration should also be given to the specific identification of uncertainties in estimation of worker risk with a plan to conduct tests or collect measurements in order to reduce uncertainty.

Suggested Improvement: The DBVS Project should consider updating its top-tier documents to ensure consistency in safety goals, performance metrics, and implementing requirements

Safety-related project documents (Project Execution Plan [PEP], PrHOA, PDSA) have been developed at different times with varying objectives throughout the DBVS Project lifetime. As a result, there are inconsistencies both within and between documents that cause confusion with respect to the intentions and commitments of CH2M HILL in matters important to the safety basis and safety performance. Also of concem is the creation of additional documents outside the framework of the project document structure. These matters could present difficulties and unnccessary complications in the development, approval, implementation, and maintenance of the DBVS safety basis.

The project should update top-tier DBVS documents to ensure consistency in safety goals, performance metrics, and implementing requirements. The ORP should issue a statement of overall radiological and chemical and industrial safety objectives. $\mathrm{CH} 2 \mathrm{M}$ HILL and AMEC should translate the safety objectives into realistic goals and performance measurcs. The project should develop a clear statement of the intention and implications of the final Hazard Categorization and perform updates to safety-related project documentation to uniformly reflect those intentions. The project should implement document configuration management and appropriate safety-related review of changes. 
Suggested Improvement: The DBVS Project should consider more closely aligning its safety documentation with STD-3009 guidance and giving greater consideration to DBVS as a stand-alone facility with unique operational characteristics The DBVS safety documentation appears too put much reliance on the existing Tank Farms DSA rather than developing a unique safety analysis. This could have two unintended effects: (1) incidents where less information is provided in the DBVS-specific safety basis than is indicated in the guidance of DOE-STD-3009, and (2) a potential that the rationale for the derivation of the DBVS-specific safety basis is not always clearly explained. Closer alignment with STD-3009 guidance and greater consideration of the DBVS as a stand-alone facility with unique operational characteristics will produce a more understandable and comprehensive safety basis. .

Consideration should be given to the development of bounding and representative accidents using the hazardous conditions identified and binned in the DBVS PrHOA. Consideration could be given to cither the preparation of simple scoping calculations more tailored to the configuration and conditions of the DBVS, or a more comprehensive discussion of why the Tank Farms analysis is applicable to the DBVS. Consideration should also be given to the identification of a set of operational modes (as well as anticipated abnormal conditions and their recovery), followed by a process to verify that the selected controls are applicable and sufficient.

Suggested Improvement: The DBVS Project should strengthen the presentation of its commitment to $\mathbf{A L A R A}$ implementation in top tier project documents The DBVS Project has performed a solid review of the design-to-date, documented in the ALARA analysis (RPP-23113, Revision 5); however, some top-level project documentation (e.g., RPP-17403 and RPP-17807) does not adequately reflect the project's commitment to ALARA implementation. The CH2M HILL's PEP discusses ALARA only in the context of radiological exposure. The $\mathrm{CH} 2 \mathrm{M}$ HILL Radiological Control organization has the only explicitly defined responsibility for ALARA; design agent responsibilities are stated briefly and generally. The ALARA-related information in the PEP and the DBVS System Specifications is very brief and of less detail than that associated with other enginecring standards. These descriptions and depictions imply a limited emphasis on ALARA in design - both in terms of the hazards considered and in terms of the roles and responsibilities across the project to implement ALARA principles. The text of the top tier Project documentation should be modified to accurately reflect the project's commitment to ALARA as well as the other aspects of safety in design and operations. 


\section{Conclusions}

The Expert Revicw Panel completed a detailed evaluation of the technical basis of the DBVS system design. Details of the evaluation are discussed below and in the detailed sub-team reports included in RPP-31337. At a summary level, the team directly addressed the primary questions posed by the ERP charter, namely,

Are there any flaws in the current design or operational plans that would prevent the DBVS system from meeting safety or technology demonstration objectives?

No fatal flaws were found. However, the DBVS, as currently structured, may not mect two of five mission objectives:

- Gather pilot plant operability data

- Develop the overall life cycle system performance of bulk vitrification and produce a comparison of the bulk vitrification process to building a second $\mathrm{L} \Lambda \mathrm{W}$ Immobilization facility or other supplemental treatment alternatives as provided in M-62-08.

To mect these objectives the project must expeditiously develop plans to achieve the last two and develop clear success criteria to determine whether they have been met.

Additionally, there are tcchnical issues that, if not satisfactorily resolved, could significantly affect the project's ability to mect its overall mission as stated in the project JMN document.

Will the DBVS system meet minimum product quality and demonstration production rate requirements?

Although testing to date indicates that the DBVS systcm produccs a product that mects all product quality requirements, this testing has not been prototypic. Furthermore, productivity will be improved by reducing the complexity in the DBVS systems and implementing an effective nuclear safety management program.

In addition, mixer-dryer, off-gas system, and integrated system testing and evaluation must be completed before the production rate can be reliably estimated.

Is the tcchnical basis of the DBVS flow sheet sound?

A detailed project flowsheet has been developed which is an important source of design information. However, much of the flowshect information is based on 
unverificd assumptions. Focused development efforts to validate key flowsheet assumptions are necessary.

Is the DBVS Equipment and Facility design basis adcquate to bound the construction and opcrating costs for the demonstration?

Modifications to the design and additional vendor testing over a wider range of operating and upset conditions are necessary. Lack of project expericnce with dry waste handling, mixer/dryer, and off-gas treatment systems make it difficult to bound operating costs. With respect to construction costs, no additional process steps were identified as being necessary.

What are the primary outstanding safety and technical risks/uncertainties for the DBVS?

Potential safety issues, including the confincment strategy, implementation of an effective ISM program, and preparation for response to off-normal events, will need to be addressed to safely exccute the DBVS Project.

The primary technical risks are associated with the forms of technetium, the complexity of the process, flow of dry waste feed, the ability to control the drying process, prevention of secondary phases in the melt box, balancing of the off-gas systems, and the performance of the Sintered Metal/Mesh Filters.

In conclusion, bulk vitrification is a technology that requires further development and evaluation to fully determine its potential for meeting the Hanford waste stabilization mission. The key focus of the project should be on adequately cstimating the life-cycle cost and risks of the bulk vitrification process for comparison with other altematives by DOE. The project must define the compositional and process operating range over which the technology can be expected to be successful.

No issues that would jeopardize the overall DBVS mission were found. However, there are technical issues that, if left unmitigated, could result in failure to meet project objectives. In addition, there are a number of areas of concern that need technical and management attention. We believe that it is important that the issues identified by this review be addressed in the near term.

The team acknowledges that the DBVS Project tcam has already initiated scveral actions to address the issucs identified by the ERP. In the future, the project should conduct technical reviews at key decision points to assure that these issues and others that may arise are identified and resolved in a timely manner. 
RPP-31314

\section{APPENDIX A}

CHARTER 
CH2M HILL Hanford Group Inc. (CH2M HILL) is conducting an extemal review of the Demonstration Bulk Vitrification System (DBVS) to assure that the technical basis for the demonstration facility design is adequate to meet the objectives of the DBVS project, as stated in the Project's System Specification RPP-17403. The primary purpose of this review is to assist the DBVS project in the finalization of a defensible technical basis and identification of risks and uncertainties associated with the Project's planned technical approach. The DBVS project must have a credible cost and schedule to proceed into construction and operation. This can only be achieved with a sound technical basis for the system design.

The DBVS review scope involves formation, coordination, and performance of a DBVS Expert Revicw Panel (ERP), whose objective is to review selected aspects of the DBVS project and provide recommendations to the CH2M HILL project team that will enhance the likelihood of overall DBVS project success.

The review team shall focus their evaluation on the effectiveness of the DBVS design as defined in the reference and supporting documents that will be provided to the team. The objective of the review is to validate that the DBVS system, as designed, meets the requirements defined in the system specification, is expected to produce a waste product that meets Integrated Disposal Facility (IDF) disposal requirements, and can be expected to receive operational approval by DOE authorities. To this end the ERP work shall focus on:

Identifying flaws in the design or opcrational plans that would prevent the DBVS system from mecting technology demonstration objectives

Determining if DBVS is expected to meet product quality and production rate requirements Evaluating the technical soundness of the DBVS flowshect Determining if the DBVS equipment and facility design basis is of sufficient detail to adequatcly bound the construction and operating costs Identifying DBVS technical risks or uncertainties

\section{SCOPE OF REVIEIV}

The review will focus on these five primary technical subject areas:

- Mission Integration - This subject area review is intended to focus on the overall integration of the DBVS project into the Hanford Site's mission supporting tank waste treatment. This part of the review scope is intended to focus on the flowdown of mission performance requirements that the DBVS project has been tasked to demonstrate.

- Flowsheet - This subject area review is intended to focus on the DBVS overall flowsheet. This review shall be limited to those systems that are specific to the internal boundaries of the DBVS project, and is not intended to include secondary support systems such as effluent treatment or utility supply. The need to extend 
the review to any of the secondary support systems will be evaluated on an individual basis as the need arises.

- Vitrification System - This subject area review is intended to focus on the design of the vitrification system, and shall include specific evaluations of the following arcas:

- Testing and Scale-Up Program

- Waste Package and Glass Recipe Formulation

- Refractory and Containcr Design

- Primary Supporting Equipment - This subject area review is intended to focus on the design of the major supporting equipment needed to ensure functionality of the vitrification system, and shall include specific evaluation of the following areas:

- Feed Mixer and Dryer Equipment

- Off Gas Trcatment Equipment

- Nuclear Safety and Operations - This subject area review is intended to focus on the ability of the system to mect nuclear safety and operational standards required for a RCRA permitted research and development pilot scale facility. This review shall include specific evaluation of the following areas:

- Nuclear Safety and Authorization Basis Requirements

- Operations and Maintenance Feasibility

\section{MEMBERSHIP}

The ERP shall consist of the five Review Subject Leads and a number of Subject Matter Experts, as deemed appropriate by the CH2M HILL Project Lead. One of the Review Subject Leads will be designated by the CH2M HILL Project Lead as the ERP Lead and shall be responsible for coordinating and communicating the efforts of all ERP members.

The team members will be independent of the current DBVS project, have a national reputation and experience, with appropriatc academic, technical, or real-world management backgrounds. CH2MHLL will identify appropriate candidates for the various positions within the ERP with concurrence of ORP and EM Project Recovery.

\section{RESPONSIBILITIES}

\section{CH2M HILL Review Manager}

The review manager is responsible for identifying and selecting the expert panel, organizing technical prescntations, and providing the documentation that is the subject of the review. The review manager is responsible for the overall working schedule, arranging for onsite and offsite mectings, facility arrangements for the team while onsite, progress reporting, and issue resolution. The review manager will assist the team with the preparation and review of the interim and final reports, and will facilitate the resolution of any technical disagreements between team leaders and/or membership. 
The revicw manager will assure that DOE, Ecology, and DNFSB representatives are notificd of key mectings and summary progress reports.

\section{Cl12NI HILL DBVS Project Manager}

The DBVS Project Manager is the primary customer for this extemal review. He is responsible to work with the Review Manager to assure that current project information is made available to the ERP, and that key members of the project technical staff (CH2M HILL and subcontractors) are made available for reasonable interaction with the various teams so that technical information, questions, and clarification can be achieved efficiently.

\section{Office of River Protection}

ORP shall review and concur with the ERP member selection and facilitate DOE Office of Environmental Management (EM) concurrence, as necessary. ORP will participate as

an observer during the various meetings and progress reporting, will review the interim and final reports, and will provide comments to the CH2M HILL Project Manager in a timely fashion.

\section{EM Office of Project Recovery}

EM Office of Project Recovery shall review and concur with the ERP member selection in a timely fashion. Project Recovery staff may participate as an observer in the various mectings and progress reports. Project Recovery will assure necessary communication with other EM entities that have an interest in the progress and outcome of this review, and will arrange for any necessary EM briefings or mectings that may be required.

\section{External Review Panel}

The panel is primarily responsible to develop a reasonable revicw schedule, identify needed information, conduct a professional review, resolve internal technical differences of opinion, organize the final report, resolve comments on report drafts, and produce a high quality review report. The panel reports to the $\mathrm{CH} 2 \mathrm{M}$ HILL review manager, who will work to facilitate the efforts of the team, and will be the final authority to resolve issues of review scope, conflicts with the DBVS project resources; and intemal and external schedule conflicts.

\section{PERIOD OF PERFORIIANCE}

The ERP work is expected to begin in May 2006 and be completed before the end of September 2006. The ERP reviews shall include a combination of Hanford Site interviews and information gathering sessions, and independent document reviews that may take place at locations convenient to the individual reviewer and associated review subject team. The primary deliverable for this work will be a final report of ERP review activitics and recommendations delivered no later than September 29, 2006. The review team is expected to work with the CH2M HILL project lead to conduct a review of the draft product with an identified review team, work to resolve comments, and produce the final document. 
RPP-31314

Approved By:

Signature on file

Roy Schepens, Manager

Office of River Protection
Signature on file

Mark Spears, President

CH2M HILL Hanford Group, Inc. 


\section{APPENDIX B}

BIOS 


\section{Dr. Chris Burrows \\ Senior Vice President \\ Technology \& Engineering Energy Solutions}

Dr Burrows has almost 40 years of engineering and management cxperience in a wide range of fields, including acronautical and nuclear engineering. He has broad experience in both nuclear fuel and waste management, and has managed major capital programs in both of these areas. In addition to his experience in general and project management, Dr Burrows has led significant technical and engineering teams and held senior positions in both strategic development and quality assurance. Dr Burrows' formal qualifications are in Mechanical Enginecring, but over the last 15 years his skills have developed more into General and Project Management. Dr. Burrows experience includes working in both the UK and Europe and has spent the last 7 years working in the USA. 


\section{Dr. William Ibbs}

Senior Consultant/Professor

University of California/Berkeley

Dr. Ibbs has extensive international \& domestic consulting experience in construction labor productivity issues; schedule disruption, delay \& acceleration; injuries; project planning \& control systems; and standard of care. Dr. Ibbs assignments have been throughout the Pacific Rim, Middle East, Europe and U.S. His industry experience involves engineering-construction, technology, petrochemical, military, healtheare, manufacturing, \& cducation projects. Dr. Ibbs has authored $170+$ papers in scholarly joumals, books, and magazines and has extensive trial, arbitration, and mediation experience. 


\section{Douglas Johnson}

\section{Senior Program Manager}

Mr. Johnson has 30 years of professional experience including eighteen months providing corporate management, operational readiness, and tcchnical advisory support to a number of BWXT managed activities and DOE Category II nuclear facilities. He has 28 years providing successful leadership and sound management in the U.S. Navy's nuclear submarine force. Mr. Johnson's experience includes 15 years of senior and executive level management of submarine technology, weapons, and nuclear propulsion programs. He has achieved excellent standards of performance managing all aspects of reactor. safeguards, maintenance and modemization, opcrational readiness, and training and certification programs. 
RPP-31314

\section{Dr. Steve Krahn}

Senior Technical Director

Perot Systems Government Services

Dr. Krahn has 28 years of general, technical project management and engineering experience in positions of increasing responsibility in government, private industry, and the military. His technical and project management highlights include: technical leadership of safety oversight for an independent federal agency; chairing independent safety review boards for two major Department of Energy (DOE) facilities and an NRC regulated plant. He has chaired the Tank Farm Senior Safety Review Board, providing nuclear safety oversight for the Tank Farms at the Hanford Site since July 2001; chaired the independent Criticality Safety Committee advising BNFL Inc at Oak Ridge from December 2002 to June 2005; was named to lead the Independent Review Team, providing nuclear work management reviews, within the Nuclear Materials Technology Division at the Los Alamos National Laboratory in November 2003 and Chairs the Independent Review Board for the Metropolis Technical Works, an NRC-regulated fucl fabrication facility. 


\section{Dr. Edward Lahoda \\ Consulting Engineer Westinghouse}

Dr. Lahoda has consulted in chemical processing for Westinghouse Science and Technology, Westinghouse Nuclear Fuels Division, DOE at West Valley, Savannah River, ITP, Hanford, and Femald. He is a member of the National Academy of Sciences . review panel for HLW processing at Idaho and in the DOE complex. Dr. Lahoda managed, developed, designed, implemented, and provided field support for the Westinghouse Soil Washing and High Temperature Thermal Desorption processes for contaminated soils; developed, tested, designed, and supported implementation of waterglass treatment technology for cleaning process water and ground water remediation; and designed and managed the construction, permitting, and equipping of the Environmental Technologies Testing Laboratory used for bench scale testing of soil remediation processes and water cleaning. 
Dr. John R. Longenecker

President

Longenecker \& Associates, Inc.

Dr. Longenecker has over 30 years experience in the energy industry in the areas of project management, strategic planning, regulatory compliance, independent assessment, and quality assurance in various programs including environmental remediation, national defense, nuclear reactor development and operations, waste management, and advanced technology development and deployment. Mr. Longenecker's expericnce with DOE programs include serving on review and advisory panels at Los Alamos National Laboratory, Lawrence Livermore National Laboratory, the Yucca Mountain Project, Fluor Hanford, the Hanford Tank Farms, and the Office of River Protection. His duties include performing management assessments for many DOE projects, and programs including the Yucca Mountain High Level Waste Project, the Idaho Spent Fuel Project, and the Lawrence Berkeley National Laboratory. In 2000, Mr. Longenecker and several Longenecker \& Associates staff served as members of a DOE rcview of the TWRS project that was mandated by Congress. Mr. Longenecker also serves as Managing Director and Working Group Coordinator of the U.S. Department of Energy's Energy Facility Contractors Group. 


\section{Dr. Robert Bruce Matthews Consultant}

Dr. Matthews has 30 ycars of scientific and engineering experience in nuclear technologies with a primary focus on special nuclear materials, nuclear reactor fuels, and nuclear facility operations. He spent eight years as a Research Scientist at Atomic Energy of Canada where he developed advanced nuclear fuels and structural materials for the CANDU reactor. He subsequently spent two years as a Research Scientist at Pacific Northwest Labs working on proliferation resistant fuels for advanced nuclear power systems. Dr. Matthews has worked as a line and program manager at Los Alamos National Laboratory since 1980, and has been involved in Department of Energy programs in stockpile stewardship, nuclear materials disposition, environmenta] management, and space and terrestrial nuclear power systems. He was Director of the Nuclear Materials Technology Division from 1993 to 1999 and was responsible for the TA-55 Plutonium Facility and the Chemistry Metallurgy Research Building. He has direct experience in nuclear facilities management including operations, construction, regulatory compliance, integrated safety management, and safeguards and sccurity. Dr. Matthews is the author or co-author of over eighty joumal publications, conference proceedings, and technical reports. He initiated the international Plutonium Futures Conference and is a Fellow of the American Nuclear Society. 


\section{Dr. Arun S. Mujumdar}

National University of Singapore

Dr. Mujumdar has experience in industrial R\&D in the United States, as well as postdoctoral R\&D experience in an industrial research institute in Canada. Aside from providing training and professional development courses to many industrial organizations in several countries, Dr. Mujumdar has provided technical consuitation in various aspects of drying and heat transfer problems to a plethora of companies. He received the first IDS award for Innovation in 1986 for his work on superheated steam drying of paper and then in 1998 his excellent research contributions were recognized via the prestigious Procter and Gamble Award. 


\section{Dr. Ian L. Pegg \\ Catholic University of America}

Dr. Pegg is the Associate Director of the Vitreous State Laboratory at The Catholic University of America (CUA). His research interests include the materials science and structure of glasses, optimization of glass compositions for use in nuclear waste disposal, leaching mechanisms and the chemical durability of glasses, high-temperature properties of glass melts, and high-temperature materials interactions with glass melts, as well as the fundamental statistical thermodynamics of the bulk and interfacial properties of multicomponent fluid mixtures. Dr. Pegg has directed numerous waste vitrification studies involving the development and characterization of glass formulations and the demonstration and scale-up of Joule-heated melting processes. He was the Principal Investigator for the vitrification development program that supported the Duratek, Inc. M-Area facility, the world's largest joule-heated radioactive production meiter. 


\section{Joseph M. Perez, Jr \\ Advisory Engineer \\ Washington Group International}

Mr. Perez joined Washington Group International in 2001 as an Advisory Engineer in the Research and Technology Group of the Hanford Waste Treatment Plant. His initial assignment was team lead for the R\&T HLW and LAW vitrification flowsheet testing activities. In 2005 he also assumed responsibility for waste form testing, modeling and product qualification work scopes. Responsibilities included managing team member assignments and performance and providing technical oversight and management of subcontractor vitrification and laboratory testing activities (defining work scope, witnessing testing activities, reviewing and accepting technical deliverables, and monitoring of schedule and budget performance) and integrating research results into engineering and process operations functions. Mr. Perez was also the Principal Investigator for several DOE Tank Focus Area tasks. These include vitrification testing and assessment of the INEEL HLW flowsheets, melter and waste form technology assessments, and evaluation of Russian and French induction heating vitrification technology. 
Dr. M. John Plodinec

Senior Advisory Consultant

Savannah River National Laboratory

Dr. M. J. Plodinec is a Senior Advisory Consultant with the Savannah River National Laboratory, currently acting as Science Advisor. In this role, he is the lab's "Science Guardian," and responsible for fostering strategic university partnerships. Dr. Plodinec rccently retumed to SRNL after eight years at Mississippi State University.

Dr. Plodinec is an intemationally recognized expert in nuclear waste characterization, vitrification, and disposition. During his 22 year involvement with the Department of Encrgy's Defense Waste Processing Facility (DWPF) - the United States' first and the free world's largest radioactive waste vitrification facility-Dr. Plodinec had an impact on every aspect of the DWPF process, including characterization of the waste, materials tcsting and performance evaluation, and proof testing of the canister closure to ensure leaktightness. Dr. Plodinec was also the primary technical lead for the DWPF product qualification program. He managed the $\$ 40$ million dollar DWPF product qualification program within SRNL. In this latter role, Dr. Plodinec had responsibility for achieving concurrence from the regulatory community, and acceptance by the public. 


\section{Richard D. Porco \\ Vice President, Power and Thermal Products Ellis \& Watts International}

Mr. Porco has over thirty-five years experience in the engineering, design, and development of HVAC products and systems for nuclear, military, and environmental facilities throughout the world. He was a member of the industry response team at Three Mile Island. He is also President of RDP Consulting Services, providing design, fabrication, and problem-solving expertise for high efficiency filtration, carbon adsorption, and contaminant control systems.

Mr. Porco is Vice Chaiman of the American Socicty of Mechanical Enginecrs Board on Nuclear Codes and Standards (BNCS) and Chairman of the Committee on Board Operations. He is Past Chair of the ASME Main Committee on Nuclear Air and Gas Treatment (ASME Code AG-1). He is a past President of the International Society of Nuclear Air Treatment Technologies (ISNATT).

Mr. Porco is a contributing author of the DOE Nuclear Air Cleaning Handbook, DOEHDBK-1169-2003. He serves on Technical Review Panels for the Institute For Regulatory Science evaluating technology such as "Alternate Metallic High Efficiency Particulate Air Filtration Systems" and "Alternative Ceramic High Efficiency Particulate Air Filtration Systems". 
Dr. Eric Tchemitcheff

Director of Technology

AREVA NC Inc. Richland Office

Dr. Tchemitcheff is a senior technical manager with 26 plus years of experience in nuclear cngineering. His focus is on radioactive waste management and transferring French tcchnology to U.S. facilities. Dr. Tchemitcheff has in-depth expertise in all aspects of radioactive waste management (including retrieval, treatment, conditioning, storage, transport and disposal activities) and of decontamination and dismantling of nuclear facilities (including spent nuclear fuel retrieval and storage, TRU waste management, decommissioning of spent fuel storage basins, plutonium-contaminated buildings and highly irradiating nuclear facilities). His management experience includes staffs of up to ninety engineers and scientists developing technical strategies, performing project definition, conceptual and detailed design, and supporting nuclear facilitics opcrations. 


\section{Dr. Ross T. Thomas BWXT Services}

Dr. Ross has 35 ycars of professional experience in the design, operation, and safety analysis of research, commercial, and defense-related nuclear facilities. In the area of nuclear safety, Dr. Ross served as the Radiation Safety Officer for two NRC licenses at VMI. Activities included ALARA reviews, radiation surveys, leak tests, calibrations, and annual reviews. He was also an executive member of the Safety Review Committee for operations at BWXT, which covered activities such as hot cell operations, radioactive matcrials analysis, radiochemistry analyses, and the handling of high burn-up spent fuel. While at NUS, Dr. Ross managed a QA department and audited hundreds of safetyrelated procedures and programs. He also has served as a startup and test engineer for two major nuclear facilities. 


\section{Dr. William R. Wilmarth \\ Savannah River National Laboratory}

Dr. Wilmarth is currently a Group Leader of the Advanced Characterization and Process research group of the Savannah National Laboratory. In this capacity, research into the treatment of high level waste resulting from nuclear processing is conducted. Dr.

Wilmarth has made significant contributions in the physiochemical understanding of high level waste and has led in the development of several process flowsheets for the removal of strontium, cesium and the actinides. Dr. Wilmarth has served as technical lead for the deployment of ion exchange materials for removal of cesium from wastes stored at Savannah River and Hanford. Other endeavors included the examination of caustic side solvent extraction of cesium removal from Savannah River wastes. Additionally, Dr. Wilmarth and his co-workers developed a strontium and actinide removal flowsheet for use in the River Protection Program. His research interests include actinide solvent extraction and ion exchange supporting the F-canyon and FB-Line plutonium processing mission. Dr. Wilmarth and others performed research into the pyrochemical processing of plutonium leading to a product acceptable for purification at Savannah River. Dr. Wilmarth has also served as the SRNL Regulatory manager (1991 - 1997). In this capacity, Dr. Wilmarth managed the implementation and oversight programs for safety analysis, chemical hygiene, environmental compliance, radiation protection and waste certification activitics. 


\section{Dr. Ray Wymer \\ Consultant}

Dr. Wymer has consulted extensively since his retirement in 1991 in the areas of radioactive waste management and site remediation for DOE and its contractors. He has had extensive consulting cxpcrience at Hanford with the Tank Waste Remediation Systems program. He assists DOE and its contractors in program reviews. He has served on committees evaluating the storage of DOE fuels in the proposed Yucca Mountain High-Level Waste Repository and chaired a committee evaluating potential vitrification proccsses for Hanford tank wastes.

Dr. Wymer has served on numerous committecs and workshops of the National Academy of Sciences that deal with DOE's waste management and site remediation activities and closure activities, and chaired one of the committees. He has chaired reviews of the Chemical Technology Division of Argonne National Laboratory and the Nuclear Science and Technology Division Oak Ridge National Laboratory.

Dr. Wymer's other activities include consulting with DOE, the U.S. Department of State and the International Atomic Energy Agency on matters of nuclear non-proliferation in the areas of nuclear fuel reprocessing and uranium enrichment by chemical exchange processes. 


\section{Dr. Frederick A. Zenz}

\section{Consultant}

Dr. Zenz has over 60 years of chemical cngineering and consulting experience. His expertise revolves around fundamental studies in fluidization, entrainment, cyclone design, dipleg sizing, flared hole trays, and light hydrocarbon separation cquipment. Dr. Zenz worked with the Army Corp of Engineers as a Special Engineer working on analysis of diffusion cascade, power frequencies, in-leakage, and computational design and properties of $\mathrm{UF}_{6}$. Dr. Zenz also worked in as a process engineer in air fractionation plant design, absorption, distillation, and correlation of physical properties of hydrocarbons and industrial chemicals. 
Page 93 of 93 of DA03589930

RPP-31314

Concurrence Signatures

The following individuals have participated in this review and concur with the report's observations and finding.

bikes kimono

Dr. Chris Burrows

Senior Vice President, Technology and Engineering

Energy Solutions

Sol ur. Lavenuctor

Drfohn Longeneckof

President, Longenecker \& Associates, Inc.

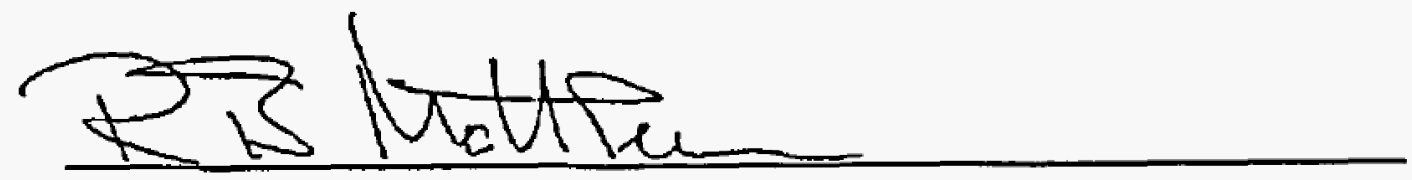

Dr. Robert Bruce Matthews

Bruce Matthews, LLC

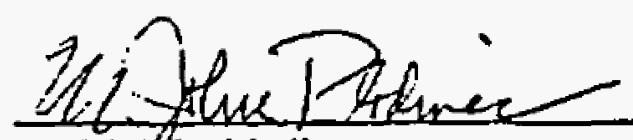

Dr. M. J Plodinec

Sr. Adv Lory Consultant, Savannah River National Laboratory

PayinG. Ny omen

Dr. Raymond G. Wymer

Consultant 